San Jose State University

SJSU ScholarWorks

Master's Theses

Master's Theses and Graduate Research

1994

\title{
Electromyographic activity of the vastus medialis obliquus during a wall squat in relation to gender and three foot positions
}

Tiffiny Shellese Shay

San Jose State University

Follow this and additional works at: https://scholarworks.sjsu.edu/etd_theses

\section{Recommended Citation}

Shay, Tiffiny Shellese, "Electromyographic activity of the vastus medialis obliquus during a wall squat in relation to gender and three foot positions" (1994). Master's Theses. 870.

DOI: https://doi.org/10.31979/etd.h6rg-8ty6

https://scholarworks.sjsu.edu/etd_theses/870

This Thesis is brought to you for free and open access by the Master's Theses and Graduate Research at SJSU ScholarWorks. It has been accepted for inclusion in Master's Theses by an authorized administrator of SJSU ScholarWorks. For more information, please contact scholarworks@sjsu.edu. 


\section{INFORMATION TO USERS}

This manuscript has been reproduced from the microfilm master. UMI films the text directly from the original or copy submitted. Thus, some thesis and dissertation copies are in typewriter face, while others may be from any type of computer printer.

The quolity of this reproduction is dependent upon the quality of the copy submitted. Broken or indistinct print, colored or poor quality illustrations and photographs, print bleedthrough, substandard margins, and improper alignment can adversely affect reproduction.

In the unlikely, event that the author did not send UMI a complete manuscript and there are missing pages, these will be noted. Also, if unauthorized copyright material had to be removed, a note will indicate the deletion.

Oversize materials (e.g., maps, drawings, charts) are reproduced by sectioning the original, beginning at the upper left-hand corner and continuing from left to right in equal sections with small overlaps. Each original is also photographed in one exposure and is included in reduced form at the back of the book.

Photographs included in the original manuscript have been reproduced xerographically in this copy. Higher quality $6 "$ " 9 " black and white photographic prints are available for any photographs or illustrations appearing in this copy for an additional charge. Contact UMI directly to order.

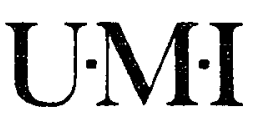

University Microfilms International

A Bell \& Howell Information Company

300 North Zeeb Road. Ann Arbor. Ml 48106-1346 USA

$313 / 761-4700 \quad 800 / 521-0600$ 
Order Number 1359059

Electromyographic activity of the vastus medialis obliquus during a wall squat in relation to gender and three foot positions

Shay, Tiffiny Shellese, M.A.

San Jose State University, 1994

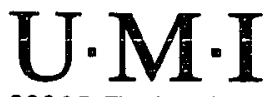

300 N. Zeeb Rd

Ann Áröor, MI 48106 
................. 


\title{
ELECTROMYOGRAPHIC ACTIVITY OF THE VASTUS MEDIALIS OBLIQUUS DURING A WALL SQUAT IN RELATION TO GENDER AND THREE FOOT POSITIONS
}

\author{
A Thesis \\ Presented to \\ The Faculty of the \\ Department of Human Performance \\ San José State University \\ In Partial Fulfillment \\ of the Requirements for the Degree \\ Master of Arts
}

by

Tiffiny Shellese Shay

August, 1994 
(C) 1994

Tiffiny Shellese Shay

ALL RIGHTS RESERVED 
APPROVED FOR THE DEPARTMENT OF HUMAN PERFORMANCE:
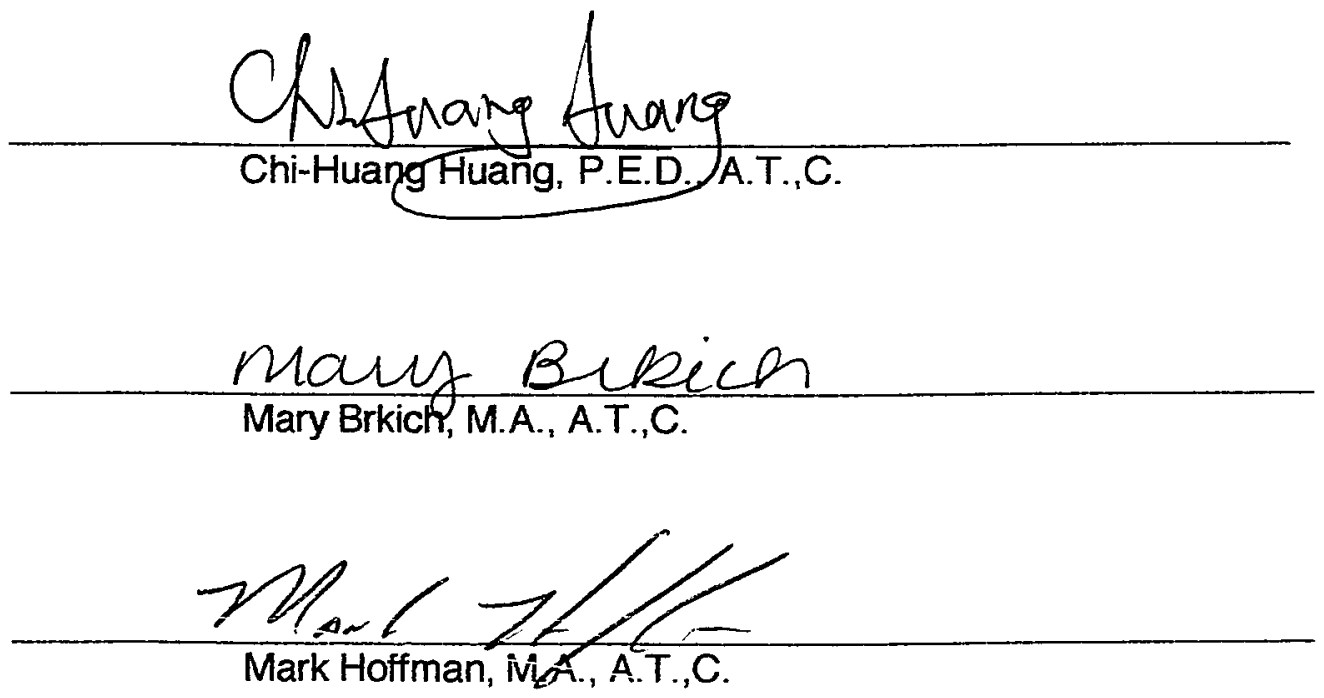

APPROVED FOR THE UNIVERSITY:

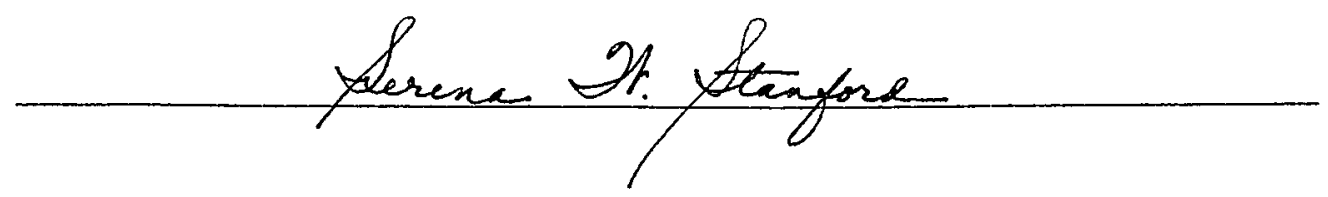




\section{ABSTRACT \\ ELECTROMYOGRAPHIC ACTIVITY OF THE VASTUS MEDIALIS OBLIQUUS DURING A WALL SQUAT IN RELATION TO GENDER AND THREE FOOT POSITIONS \\ by Tiffiny Shellese Shay}

During a rehabilitation session, patients are often required to vary their foot position during a closed kinetic chain exercise in an effort to isolate certain muscles. This study compared the electromyographic (EMG) activity of the vastus medialis obliquus (VMO) during the eccentric portion of a wall squat (knee flexion of 60 degrees) with the feet in three different positions. During the pilot study, five subjects performed 15 continuous repetitions of the wall squat for each foot position. Subjects were weighed using a digital scale. Intensity of the exercise was controlled by having the volunteers perform the wall squat holding dumbbells weighing 20,30 , and 40 percent of their body weight. The Orion 8600 Biofeedback System ${ }^{\circledR}$ was used to record the EMG data. Surface electrodes were positioned over the VMO of the dominant leg of the volunteers. Results of the pilot study showed that dumbbells weighing 30 percent of body weight increased VMO activity the most. For the main study, muscle activity was measured during fifteen separate repetitions of the wall squat while holding dumbbells weighing 30 percent of body weight. A two-way ANOVA with repeated measures was used to analyze the data. Results showed no statistically significant difference in eccentric VMO activity between the three foot positions in relation to gender. Reliability of the data was good and the study showed practical significance. 


\section{ACKNOWLEDGEMENTS}

The author wishes to express deep appreciation to the following individuals who contributed to this study: Mike Huang P.E.D., A.T.,C., Thesis Committee Chairman, for his guidance and critical review of the study; Mark Hoffman M.A., A.T.,C., Committee member, for his critical review of this study; Mary Brkich M.A., A.T.,C., Committee member, for whom I have tremendous respect both personally and professionally, who spent countless hours helping me with everything!

Special thanks are extended to Dr. Barbara Conry for her guidance and assistance throughout this investigation.

In addition, I would like to thank Dr. Bethany Shifflett for her expert statistical advice.

Furthermore, I am especially grateful to my family and friends for their encouragement which kept me going when I felt like giving up.

And finally, to my husband Patrick, the most important person in my life, who had endless patience to put up with me through this whole experience. I love you and thank you! 


\section{Table of Contents}

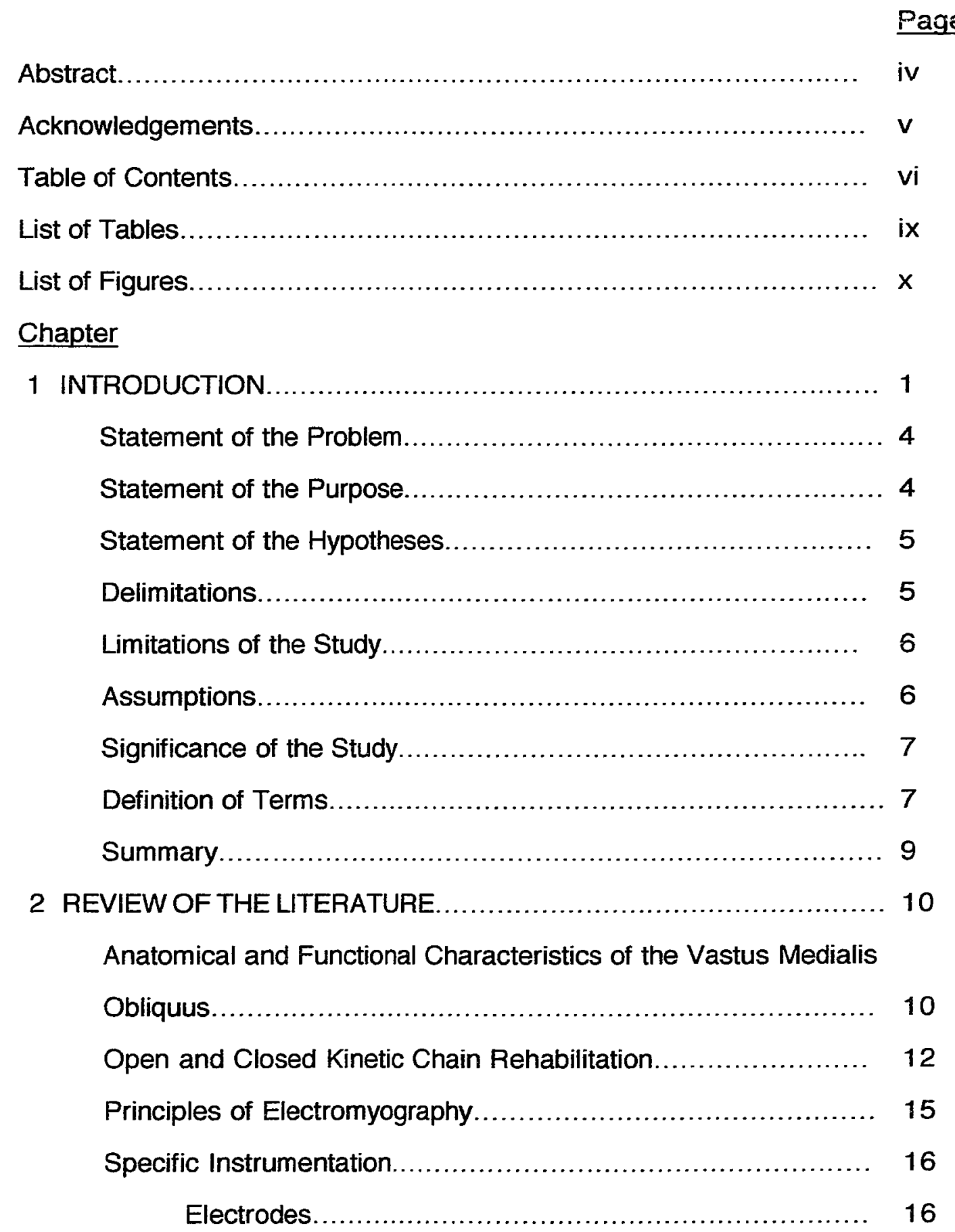


Table of contents (continued)

Amplifier.................................................. 16

Filtering Electromyographic Data......................... 17

Recording and Displaying Devices....................... 17

Grounding Device...................................... 18

Quantification of the Electromyographic Data............... 18

Electromyographic Studies Involving the Lower Extremity........ 18

Validity and Reliability of Electromyography..................... 22

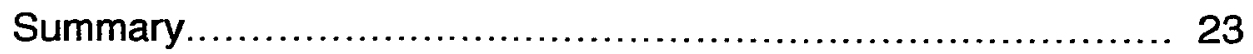

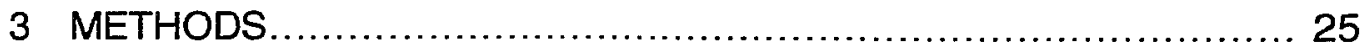

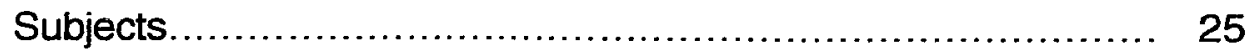

Instrumentation ................................................. 26

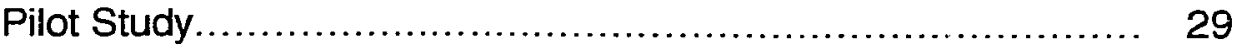

Pilot Study Results............................................. 32

Data Collection.................................................. 33

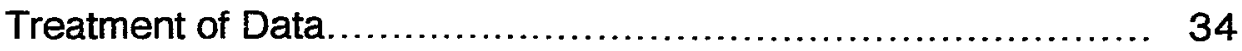

4 ANALYSIS AND DISCUSSION OF DATA .......................... 35

Demographics for the Subjects ................................... 35

Validity and Reliability of Main Study............................. 36

Main Study Results................................................ 37

Discussion....................................................... 40

5 SUMMARY, CONCLUSIONS AND RECOMMENDATIONS.......... 44

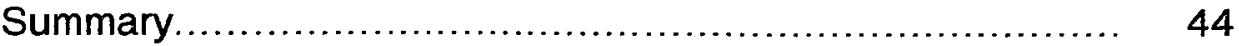

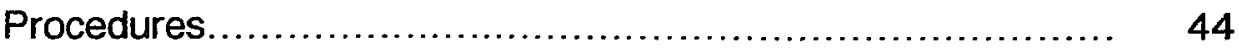

vii 
Table of contents (continued)

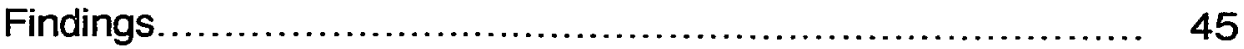

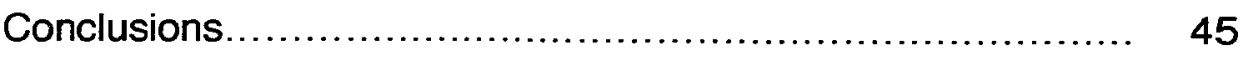

Recommendations for Further Study .............................. 45

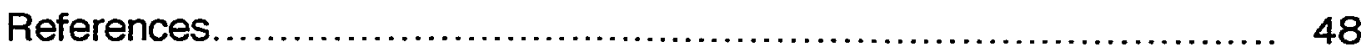

Appendix A - Consent Form ............................................... 52

Appendix B - Questionnaire .............................................. 54

Appendix C - Randomly Chosen Foot Positions \& Weight Lifted........... 55

Appendix D - Main Study Randomly Chosen Foot Positions ............. 56

Appendix E - Pilot Study Subject Demographics......................... 57

Appendix F - Main Study Subject Demographics.......................... 58

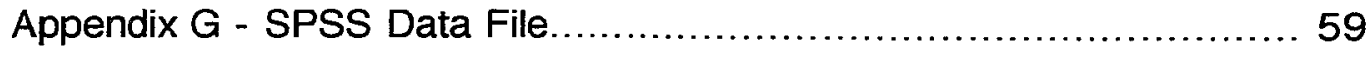

Appendix H - SPSS Definition File........................................ 60

Appendix I - SPSS Program File ........................................ 61

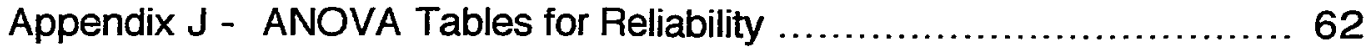

Appendix K - Calculations for Practical Significance........................ 63 


\section{LIST OF TABLES}

\section{Page}

Table 3.1 Group Peak Eccentric EMG Values from Pilot Study........... 32

Table 4.1 Mean Age, Body Weight, and Distribution of Dominant Lower Extremity for Female and Male Subjects................ 36

Table 4.2 Male and Female Means and Standard Deviations of Peak Eccentric EMG Values for Three Foot Positions.....

Table 4.3 Two-Way Analysis of Variance with Repeated Measures on Foot Position in Relation to Gender................................. 39 


\section{LIST OF FIGURES}

\section{Page}

Figure 3.1 Squat Limiter..................................... 27

Figure 3.2 Foot Template.......................................... 28

Figure 3.3 Electrode Placement................................ 30 


\section{CHAPTER 1}

\section{INTRODUCTION}

Considerable attention has been given to quadriceps strengthening in knee rehabilitation. Anatomically, it is the major force in providing dynamic stabilization for the knee joint (Nicholas \& Hershman, 1986). The importance of the vastus medialis obliquus (VMO), specifically, has been discussed thoroughly in the literature (Basmajian \& DeLuca, 1985; Francis \& Scott, 1974; Hanten \& Schulthies, 1990; Paulos, Rusche, Johnson, \& Noyes, 1980; Pevsner, Johnson, \& Blazina, 1979; Souza \& Gross, 1991; Tremain, 1993; Westfall \& Worrell, 1992). Functionally, its importance lies in that if there is a muscular imbalance, with the vastus lateralis being more powerful than the vastus medialis, there is a tendency for the patella to be pulled laterally (Roy \& Irvin, 1983). Therefore, whether the patient has a patellofemoral problem or has had a ligament reconstruction, the VMO is often targeted for strengthening. With the growing importance of combining proprioception and functional strengthening in rehabilitation, the current trend for knee injuries is to utilize closed kinetic chain exercises throughout a patient's rehabilitation program (Case, DePalma, \& Zelko, 1991; Blair \& Wills, 1991; Paulos, Wnorowski, \& Beck, 1991; Prentice, 1994).

Research investigating closed kinetic chain exercises in knee rehabilitation has been somewhat limited. Most of the focus has been on quadriceps strengthening through isometric and isokinetic exercises, which are referred to as open kinetic chain exercises. However, some commonly used isometric exercises have been researched as ineffective for developing 
quadriceps strength (Karst \& Jewett, 1993); and despite the fact that isokirietic exercise causes excessive strain on the anterior cruciate ligament, many knee rehabilitation protocols continue to include or even emphasize these exercises (Palmitier, An, Scott, \& Chao, 1991).

A review of the current research investigating closed kinetic chain exercises indicated several advantages over open chain exercises (Blair \& Wills, 1991; Bunton, Pitney, Kane, \& Cappaert, 1993; Case et al., 1991; Graham, Gehlsen, \& Edwards, 1993; Palmitier et al., 1991; Yack, Collins, \& Whieldon, 1993). Gray (1993) outlined the advantages of closed kinetic chain exercises with a comparative analysis between the two techniques. He advocated the use of closed kinetic chain exercises for patients with anterior cruciate ligament $(A C L)$ deficient knees because axial loading limits anterior tibial displacement. In addition, closed kinetic chain exercises were recommended over open kinetic chain exercises because a co-contraction of the hamstring muscles and quadriceps is induced. This decreases the amount of stress placed on the ACL.

Commonly used therapeutic exercises which utilize closed kinetic chain principles are the step-up (Brask, Lueke, \& Soderberg, 1984), stairclimbing (Cook, Zimmerman, Lux, Neubrand, \& Nicholson, 1992), and the squat (Tremain, 1993). To date, the effectiveness of these exercises has not been well-documented. Only two studies (Graham et al., 1993; Yack et al., 1993) have compared open and closed kinetic chain exercises for the lower extremity. It is important to note, for discussion purposes later in the paper, that the squat was utilized in both of these studies. The purpose of the study by Graham et al. was to determine the EMG activity ratio of quadriceps to hamstrings occurring in 
the following exercises: the lateral step-up, leg extensions, unilateral onelegged squats, and stairclimbing. The purpose of the Yack et al. study was to quantify the amount of anterior tibial displacement occurring in ACL deficient knees during resisted knee extension and a parallel squat. In both studies, it was concluded that the closed kinetic chain exercises placed less stress on the anterior cruciate ligament, as indicated by anterior tibial displacement.

No studies to date have specifically investigated foot position while performing the squat. According to Fahey (1986), when discussing postsurgical knee rehabilitation exercises, in the early intermediate stage "you can allow squatting to ninety degrees with knees protected and feet pointing straight ahead" (p. 376). Merten and Potteiger's 1991 article discussed proper techniques for the squat with weight training. They concluded that the feet should be flat on the floor, shoulder width apart and parallel, with the toes pointed slightly outward. Tremain's 1993 article stated that proper biomechanical form was having the patient keep both knees in line over their shoes as they performed the squat. In the study by Yack et al. (1993), subjects performed the squat with their feet in $\mathbf{2 0}$ degrees of external rotation and shoulder width apart. No studies where found in which subjects executed the squat with their feet internally rotated.

The squat known as the "king of exercises" is a quick and efficient method of strengthening the lower extremity (Merten \& Potteiger, 1991). Chandler and Stone (1991) explained that the squat "can be an important component of a training program to improve the athlete's ability to forcefully extend the knees and hips, and can considerably enhance performance in many sports" (p. 51). The limited research on the squat as a closed kinetic 
chain exercise for lower extremity strength, as well as the conflicting information on foot position during the closed kinetic chain exercises indicates a need for further study.

\section{Statement of the Problem}

The problem of the study was to compare the electromyographic activity of the vastus medialis obliquus during a wall squat with the feet in three different positions. More specifically, this study was undertaken to compare the level of eccentric muscular activity of the VMO during a 60 degree wall squat, with the feet in neutral position, externally rotated 20 degrees, and internally rotated 20 degrees and in relation to gender. Gender is an important variable in this study because the female population tends to experience more patellofemoral disorders than the male population.

\section{Statement of the Purpose}

Despite current protocols extensively utilizing closed kinetic chain exercises, limited research is available to support their use. During a rehabilitation session, patients are often required to vary their foot position during a closed kinetic chain exercise to isolate specific muscles. There has been no study to date regarding the role of a patient's foot position during closed kinetic chain exercises, specifically the wall squat, to selectively recruit the VMO. 


\section{Statement of the Hypotheses}

1. There is no significant difference in eccentric VMO activity during the wall squat with feet in the neutral position, externally rotated 20 degrees, and internally rotated 20 degrees.

2. There is no significant difference in eccentric VMO activity during the wall squat between males and females.

3. There is no significant difference in eccentric VMO activity during the wall squat in relation to gender with three foot positions.

\section{Delimitations}

The following delimitations in the interpretation of data and generalization of results were acknowledged:

1. Participants with prior history of a lower extremity injury with symptoms lasting for more than three days within the last two months were excluded from the study.

2. Participants were able to perform a wall squat with the feet in neutral position, externally rotated 20 degrees and internally rotated 20 degrees as executed in front of the examiner during a pre-participation screening.

3. Participants consisted of 13 male and 13 female volunteers from San José State University, ranging between 18-35 years of age.

4. Participants involved in lower extremity weight training programs in excess of two days per week were excluded from the study.

5. Only the dominant leg was tested. Dominance was established using the leg dominance test. 
6. The Orion Model 8600 Biofeedback machine with the EMG modality was used in this study.

7. Active surface electrodes were used because of ease in application, standardization of procedures, and low leveis of discomfort.

8. The Counselor ${ }^{\circledR}-$ Borg $^{\circledR}$ model digital scale was used in the study to weigh subjects.

\section{Limitations of the Study}

The study was limited by the following factors:

1. With active surface electrodes, signal attenuation may be caused by large amounts of subcutaneous fat.

2. Active surface electrodes lack sensitivity as compared to intra-muscular electrodes.

3. Dumbbells in five pound increments were used, so the subject's dumbbell weight was rounded up to the nearest five pounds.

4. Sufficient effort was exhibited by subjects performing the exercise.

5. The taped message (in the pilot study) to set the rate of the wall squat was once every two seconds.

6. No cross talk from other muscles was present.

\section{Assumptions}

It was assumed that:

1. Subjects were healthy, as they were screened for previous musculoskeletal injuries to the lower extremity. 
2. The clinician was accurate and reliable when taking goniometer measurements.

3. The clinician was accurate and reliable in visually locating the VMO and the electrode placement.

4. The test to measure leg dominance is valid and reliable.

5. The Orion Model 8600 Biofeedback System ${ }^{\circledR}$ was accurate when measuring EMG activity of the muscle.

6. The digital scale used to measure body weight was accurate and reliable.

\section{Significance of the Study}

Much of the research regarding closed kinetic chain exercises has compared them to open kinetic chain exercises. No studies have been conducted to investigate foot position during squatting activities. It is hoped that information gained from this study will provide additional knowledge as to the relationship between foot position and lower extremity muscular activity. A knowledge of the electromyographic activity of isolated muscles during a closed kinetic chain exercise with the feet in different positions may provide insight for the development of more substantiated rehabilitation protocols for patients with knee problems.

\section{Definition of Terms}

The following terms are defined in reference to their use in this study:

1. Attenuation: to reduce in strength, force, value or amount; weaken (Morris, 1981, p. 85). 
2. Closed kinetic chain exercise: a combination of several joints united successfully where the end segment is not free - as when the limb is in the support phase (Gray, 1993, p. 14).

3. Cross talk: electrical activity coming from other muscles (Turker, 1993, p. 706).

4. Dominant leg: the leg that the subject used to kick a ball (Wong, 1984).

5. Eccentric: contraction with muscle lengthening (Roy \& Irvin, 1983, p. 33) as in the "down" phase of the wall squat.

6. Leg dominance test: a functional test in which a subject kicks a ball from a specified spot to a specified distance; the leg that the subject used to kick the ball was determined as the dominant leg (Wong, 1984).

7. Open kinetic chain exercise: a combination of several joints united successfully where the end segment is free - as when the limb is in the swing phase (Gray, 1993, p. 14).

8. Root-Mean-Square Value (RMS): a term used to describe a biphasic wave form. RMS refers to the root-mean-square method of determining the equivalent area contained by the curve (Nelson \& Currier, 1987, p.13).

9. Subcutaneous fat: fat layer beneath the skin (Thomas, 1985, p. 1646).

10. Vastus Medialis Obliquus: the terminal portion of the vastus medialis muscle with its fibers at a variably increasing attachment angle of 50 to 60 degrees, and inserts into the medial portion of the patella (Nicholas \& Hershman, 1986, p. 675).

11. Wall squat: a closed kinetic chain exercise in which the subject stands upright and leans with the back against the wall to perform knee flexion at an angle of 60 degrees. 


\section{Summary}

Knee rehabilitation protocols have undergone many revisions due to research showing open kinetic chain exercises producing harmful, shearing and compressive forces, or because the exercises commonly used were unsuccessful in strengthening specific muscles. Recently, the use of closed kinetic chain exercises has been proposed as an alternative to open kinetic chain exercises for rehabilitation programs. Since there have been no studies examining foot position during these closed kinetic chain exercises (specifically the squat), additional investigations are warranted. 


\section{CHAPTER 2}

\section{REVIEW OF THE LITERATURE}

The knee has been a major research topic in the 1990's. Every aspect, from surgery to rehabilitation, has been investigated. Many new concepts have been introduced into rehabilitation in an effort to shorten patient recovery time. This chapter discusses: (a) anatomical and functional characteristics of the VMO, (b) kinetic chain rehabilitation, (c) EMG principles, and (d) lower extremity EMG studies.

\section{Anatomical and Functional Characteristics of the Vastus Medialis Obliquus}

The musculature about the knee plays an important role in both the normal functioning of the knee and in protection against injury. Nicholas and Hershman (1986) described this musculature as "occupying the anterior thigh, and with a single innervation via the femoral nerve (L2-L4), the four muscles that make up the quadriceps mechanism are the largest muscle unit in the body" (p. 674-675). The rectus femoris comprises the bulk of this mass of muscle. Crouch (1985) stated that the rectus femoris:

lies in front of the vastus intermedius and between the vastus medialis and lateralis, but unlike them, it has a double origin; one head to the anterior inferior spine of the ilium and the other to the posterosuperior rim of the acetabulum. These four muscles have a common tendon of insertion into the superior border of the patella (p. 241).

The common insertion for the four muscles is the tibial plateau distal to the patella. The attachment angles of the vastus lateralis are slight, five to ten degrees, in a lateral direction. The fibers of the vastus intermedius are almost 
straight, as are the bulk of the fibers from the vastus medialis. Only the terminal portion of the vastus medialis, the so-called vastus medialis obliquus, diverges from this pattern. It has a variably increasing attachment angle, approximately 50 to 60 degrees, as it inserts into the medial portion of the patella. Anatomically, the VMO is not a separate muscle, but rather a continuous extension of the vastus medialis. This anatomical arrangement is important due to common innervation from the femoral nerve. Nicholas and Hershman (1986) stated "the four heads function as a unit, without a selective increase in activity in the vastus medialis obliquus during terminal extension" (p. 675). According to Nicholas and Hershman (1986), the primary function of the quadriceps during gait is to prevent collapse of the flexing knee from heel strike to midstance.

According to Wallace, Mangine and Malone (1990), mechanics of the patellofemoral joint are influenced by a number of factors, one of which is the quadriceps muscles. The patella has a number of roles: (1) to increase the distance of the tendon from the joint axis, (2) to provide a smooth articular surface (rather than allowing the quadriceps tendon to articulate against the anterior surface of the femur), and (3) to protect the anterior knee. Normal function of the patella is to glide in the trochlear groove in a rhythmical pattern increasing the leaverage of the quadriceps muscle. During this activity, the patella must withstand shear and compressive forces placed on its articular surfaces.

Patellar stabilization is provided by static and dynamic mechanisms as Wallace et al. (1990) mentions:

Active stability is provided through traction of the vastus medialis with an emphasis placed on the oblique fibers of this muscle. This muscle also provides a degree of static stability through its insertion and acts with other soft tissue 
structures on the medial side of the knee to assist in providing a degree of static stability. Thus the function of the patellofemoral joint is intricately linked to movement of the tibiofemoral joint, and total knee function includes a dynamic relationship between all functional components (p. 329).

\section{Open and Closed Kinetic Chain Rehabilitation}

Wallace et al. (1990) explained that the kinetic chain concept allows us to view the action of the total lower extremity as a functional relationship. It was explained that the lower extremity acts in the open kinetic chain when the foot is off the ground and in a closed kinetic chain when the foot is in contact with a supporting surface. Wallace stated that "the significance of this difference is that the closed kinetic chain is an encapsulated system prohibiting the function of one portion (i.e., the foot) to the exclusion of the remaining parts (i.e., the knee and the hip)" (p. 330).

Gray (1993) compared open and closed kinetic chain rehabilitation techniques for the lower extremities, and contrasted between end segments, gravity, axis of motion, muscle contractions, movement, load, stress/strain, and velocity. Closed kinetic chain exercises were perceived as being superior to open kinetic chain exercises because of many factors. In open chain function the end segment, or the foot, is completely free, whereas, in closed chain function the end segment begins to lose its freedom because of its relationship to the ground and/or other environments and gravity. With closed chain function, gravity is used as an integral part of the environment; whereas with an open chain environment, the body is in a confused state of reference to gravity. Closed kinetic chain exercises utilize multiple axes of motion and the motion is both distal and proximal. Open kinetic chain motion produces motion only distal to the joint axis of motion. The contraction of muscle within an open chain 
environment is primarily concentric, whereas closed chain muscle contraction includes eccentric, concentric, and isometric muscle function. Many open chain rehabilitation techniques for the lower extremity concentrate on the isolation of movement, while the closed chain function can facilitate the dominant motions at various joints, all within an integrated system. Normal physiological loads are created through the skeletal system with closed chain rehabilitation. Loads through the skeletal system with open chain motion in the lower extremities is artificial and many times abnormal. Open chain rehabilitation of the lower extremities creates inconsistent stress and strain within the soft tissues. Many times the stress and strain is not only biomechanically inconsistent, but actually harmful. Closed chain function creates biomechanically consistent stress and strain within the soft tissues. The velocity of open chain movement with various rehabilitative techniques are many times predetermined or influenced with respect to lower extremity function. Closed chain rehabilitation techniques allow for a variable velocity.

Other advantages of closed kinetic chain rehabilitative techniques which Gray (1993) discussed relate to stabilization, environment, planes, and proprioception. Lower extremity rehabilitation in an open chain environment provides artificial stabilization, such as in the form of a strap. Stabilization within the closed kinetic chain relies on the muscles and nerves to produce normal postural mechanisms. Most open chain lower extremity environments require the patient to act upon the environment as opposed to reacting to the environment as is afforded and facilitated with the use of closed chain techniques. Closed chain rehabilitation produces a combination of motion in all three planes (frontal, sagittal, and transverse) consistent with the motion of 
joints and associated soft tissue structures, whereas open chain exercises typically occurs in one plane of motion by design. Closed chain rehabilitation accurately facilitates normai proprioceptive feedback mechanisms and strongly enforces carry-over into normal functioning activities. Open chain rehabilitation facilitates false proprioceptive feedback, with questionable carry-over feedback.

Gray (1993) also discussed how the patient reacts to the exercise. This factor can be associated with adherence to a rehabilitation program. Closed chain rehabilitation allows for a flexible pattern of exercise with numerous possibilities to accomplish the functional exercise tasks. The pattern of exercise is rigid in the open chain environment. The number of techniques for open chain rehabilitation for the lower extremity is severly limited, while the techniques for closed chain is literally unlimited. Open chain testing environments provide objectivity within the limitation of the machine or environment. Closed chain testing provides an environment for functional objectivity and, therefore, more directly relates to the function of rehabilitation and the function of the patient's normal activities. With many open chain environments the clinician's creativity is limited by the equipment. For closed chain rehabilitation, the clinician has much more freedom and must have an understanding of the reactive planes and joints of movement and the relationship of the patient to gravity. The resultant exercise in an open chain environment is non-functional. The feel the patient receives is very structured and the accompanying attitude quickly turns to a boring and therefore, poorly motivated situation. Closed chain rehabilitation reveals functional exercise with functional patterns of movement and reactive activity as seen and experienced 
in normal activities. The feel immediately transforms to a life-like feel and rehabilitation quickly becomes fun.

Bunton et al. (1993) are in agreement with Gray and have also indicated several advantages of closed kinetic chain exercises. Closed kinetic chain exercises allow more functional patterns of movement which lead to an optimal level of development of the proprioceptors. Muscle group coordination is increased through examples of progressive exercises.

Deciding when to implement closed versus open kinetic chain exercises in a patient's program is the key to successful rehabilitation. Each exercise has advantages and disadvantages and the patient's pathology will dictate which one is appropriate as the patient progresses.

\section{Principles of Electromyography}

The inclusion of electromyographic feedback during therapy programs among patients with musculoskeletal disorders has proven to be a valuable tool for clinicians. "Although EMG has been available for over four decades, relatively recent developments in instrumentation and sophisticated electronics have enabled EMG to become a powerful technique for studying muscle function and dysfunction" (Soderberg \& Cook, 1984, p. 1813). In general, EMG can be used in studies of pure function, the evaluation of results of surgical transfer of muscle, the evaluation of motor unit activity or the relationship of EMG to muscle tension. EMG can also be used for biofeedback or to study functional anatomy of muscles, excitability of motorneurons, and reflex connection of muscles (Turker, 1993). EMG is a convenient mechanism for 
studying the effects of an exercise on muscle activity if the proper equipment and methods are used.

\section{Specific Instrumentation}

\section{Electrodes}

According to Turker (1993), two types of electrodes are used in EMG recording: surface and intramuscular electrodes. The choice of electrode is dependent upon the muscle under study. For large superficial muscles, surface electrodes should be used. For small superficial muscles and deeper muscles, intramuscular electrodes should be used. There are two classifications of surface electrodes: active and passive. Active surface electrodes have high electrical input resistance. Passive surface electrodes do not have high electrical input resistance and, therefore, they are affected by changes in skin resistance. When using passive electrodes, one must clean the skin surface using 70 percent isopropyl alcohol in order to reduce the electrical resistance of the skin. In determining the number of electodes to use, bipolar recording is nearly always used. In bipolar recording, two electrodes are placed on or in the muscle, and the electrical current between them is recorded. Bipolar recording enables the noise-suppressing capacity of the amplifier to be fully utilized and avoids the disadvantages present in monopolar recording (one electrode placed on the muscle), and is therefore the preferred configuration.

\section{Amplifier}

According to Turker (1993), a differential amplifier with the following characteristics is recommended: (a) the capacity to amplify the input data by at 
least 1,000 times, (b) a frequency bandwidth appropriate for all EMG signals, (c) an amplifier input electrical resistance at least 10 times as high as the electrode-to-skin electrical resistance, and (d) a common mode rejection ratio of about $1,000: 1$ or preferably higher. The amplifier should be capable of amplifying the original sound with minimal distortion. There are a number of methods for minimizing distortion such as taping the electrodes to the skin surface, placing the amplifier within $10 \mathrm{~cm}$ of the recording electrodes, using the shortest possible leads for connecting the recording electrodes to the amplifiers, and using active electrodes.

\section{Filtering Electromyographic Data}

Because the frequency characteristics of surface EMG and single motor unit recordings are different, filtering limits should also be different. Turker (1993) stated that

for most muscles, the frequency spectrum of the surface EMG data is about 20 to $500 \mathrm{Hertz}$. The frequency values may vary depending on the thickness of soft tissue covering the muscle and fiber-type composition of the muscie. The upper and lower limits of the filters, therefore, should not eliminate any of the frequencies within this range (p. 699).

\section{Recording and Displaying Devices}

During recording, the electrical signals from the muscles must be free of mechanical artifacts, electrical noise, and cross talk. If these signals are not eliminated and the permanent records contain these unwanted signals, it would be difficult to separate them after the experiment. Permanent records of EMG data are desirable because they are a means of verifying the quality of the record, should this be necessary. Turker (1993) recommended three of the 
most common methods of creating a permanent record of these recordings: (a) use of a low-frequency-response recording device, (b) use of a high-frequency recording device, or (c) a computer program.

Electrical noise can be reduced if the following steps are taken: (a) use active surface electrodes, (b) choose a bipolar recording technique, (c) ground the subject, and (d) use very short leads.

\section{Grounding Device}

By grounding the subject through the use of an electrode which is placed on an indifferent (ie: nonmuscular) site, noise can be eliminated from the recording. It has been recommended that the ground be placed close to the recording electrodes.

\section{Quantification of the EMG Data}

The EMG trace has many measurable qualities including the amplitude, duration, and frequency of the surface EMG signals. According to Turker (1993) the raw EMG signals need to be modified using full-wave rectification and highcut filtering before they can be used quantitatively. "This modification envelops the amplitude and the frequency characteristics of the surface EMG signals so that a good estimate of the number and the frequency of the firing of underlying motor units is represented on the final record" (p. 707).

\section{Electromyographic Studies Involving the Lower Extremity}

In a study done by Wild (1982) it was established that the EMG was a valid documentation tool, especially in the measurement of isometric muscle 
contraction. Several authors have utilized EMG in their studies of isometric contractions (Hanten \& Schulthies, 1990; Karst \& Jewett, 1993; Reynolds, Levin, Medeiros, Adler, \& Hallum, 1983; Soderberg, Minor, Arnold, Henry, Chatterson, Poppe \& Wall, 1987). EMG has also been used for biofeedback and isotonic and isokinetic studies (Brask et al., 1984; Cook et al., 1992; Souza \& Gross, 1991; Sczapanski, Gross, Duncan, \& Chandler, 1991). Hanten and Schulthies (1990) measured the electrical activity of the vastus medialis obliquus (VMO) and the vastus lateralis (VL) during maximaleffort isometric contractions of hip adduction and medial tibial rotation. The results showed that the EMG activity of the VMO was significantly greater than that of the VL.

Karst and Jewett (1993) expanded on this study of Hanten and Schulthies by measuring the EMG activity of the vasius medialis obliquus (VMO), the longitudinal portions of the vastus medialis (VML), the vastus lateralis (VL), and the rectus femoris muscles. They wanted to determine whether exercises combining hip adduction with knee extension activated medial components of the quadriceps femoris muscle more than does knee extension alone. This study did not support Hanten and Schulthies (1990) conclusions. It was concluded that exercises requiring combined hip adduction and knee extension torques, such as straight leg raises with lateral rotation or straight leg raises with hip adduction, are not superior to the quadriceps sets or the standard straight leg raise exercise in eliciting an increase in the relative activity of the medial components of the quadriceps femoris.

In an earlier study by Soderberg et al. (1987), healthy subjects as well as subjects with knee pathologies were studied. EMG data were obtained from 
the vastus medialis, rectus femoris, gluteus medius, and biceps femoris muscles from the two groups during two different isometric exercises (a straight leg raising (SLR) and quadriceps setting). The EMG data collected during the SLR exercise were compared with EMG data obtained from the same muscles during quadriceps femoris muscle setting (QS) exercises. The results showed significantly greater activity of the vastus medialis, biceps femoris, and the gluteus medius muscles during QS exercises than during SLR exercises. The rectus femoris muscle was significantly more active during the SLR exercises than during the QS exercises.

LeVeau and Rogers (1980) used EMG as a biofeedback tool to determine if the vastus medialis (VM) could be trained to contract independently of the vastus lateralis $(\mathrm{VL})$ in an attempt to show that the alignment of the patella could be adjusted by muscle control. Ten subjects attended a 30-minute EMG biofeedback training session five days a week for three weeks. During the first two weeks the subjects concentrated on decreasing the muscle activity level in the $\mathrm{VL}$, through isometric contractions, while maintaining a constant percentage of the reference activity level in the VM. The muscle activity reference levels for the $V L$ and VM were determined daily from the maximum amount of weight that the subject could hoid at 170 degrees of extension of the dominant leg. The EMG unit monitoring the VM would go on without sound when the muscle activity equaled or exceeded 25 percent of the reference level. For the first five contractions, the EMG unit monitoring the VL was set so that a buzzer sounded if the muscle activity equaled or exceeded 25 percent of the VL reference level. During the third week, they tried to increase the activity level of the VM muscle. In this study significant differences were found in the muscle activity level of the 
VL over the first two weeks, the activity level of the VM over the third week, and in the difference between the VL and VM muscle activity levels from the first to the third weeks. However, the question of whether an individual could strengthen the vastus medialis independently of the other quadriceps muscles has yet to be determined.

EMG can be used to approximate tension requirements for isotonic contractions. The study by Brask et al. (1984) was designed to determine if significant differences in level of electrical activity in the vastus medialis, rectus femoris, biceps femoris, and semimembranosus/semitendinosus muscles occurred during the concentric (up) and eccentric (down) phases of the lateral step-up exercise at heights of four inches and eight inches. It was concluded that the concentric phase produced significantly greater activity than the eccentric phase at each height except for the semimembranosus/ semitendinosus muscles, where no significant difference existed.

Cook et al. (1992) conducted a similar study in which EMG activity levels were evaluated for the rectus femoris, vastus medialis, biceps femoris, gastrocnemius, and semimembranosus/semitendinosus muscles during exercise on a stepping machine and during performance of an eight inch lateral step-up. The stepping machine, in general, showed decreased activity during the knee extension phase and very little activity during the knee flexion phase when compared to the lateral step-up.

In the study done by Graham, Gehisen, and Edwards (1993), five different closed kinetic chain exercises (stairclimbing, lateral step-ups, slideboard, quarter squat, and movements on the Fitter) and one open kinetic chain exercise (leg extensions on an N-K Table) were evaluated. It was 
determined that all five closed kinetic chain exercises resulted in minimal anteroposterior shear forces at the kinee when compared with the open kinetic chain exercise. It was also concluded that the closed kinetic chain exercises appeared to be an appropriate and effective means of improving both quadriceps and hamstring strength.

This finding was also supported in the study by Yack, Collins, and Whieldon (1993). These authors quantified the amount of anterior tibial displacement which occurred in anterior cruciate ligament-deficient knees during an open (resisted knee extension on an NK table) and a closed kinetic chain exercise (parallel squat). During the parallel squat the subjects were asked to keep their back straight, their feet in 20 degrees of external rotation and shoulder width apart, while squatting no more than 90 degrees of knee flexion. It was concluded that the stress to the anterior cruciate ligament was minimized when the closed kinetic chain exercise was utilized.

\section{Validity and Reliability of EMG}

Due to the extensive research utilizing EMG to measure muscle activity, it can be assumed to be a valid documentation tool. Wild's (1992) extensive literature review confirms that EMG is well known in studying quadricep function both in healthy subjects and in patients with knee pathologies.

Reliability of a study is dependent upon the researcher's ability to obtain a strong EMG signal. According to Turker (1993) there are a number of methods for minimizing distortion in order to receive a stronger signal and therefore, increasing the study's reliability. These items were discussed earlier in the specific instrumentation section. DiFabio's 1987 article compared the 
reliability of a computerized analysis system (CAS) for determining muscle burst onset with the subjective assessments of three trained examiners. A sample of 154 randomly selected, full wave rectified and filtered EMG recordings were evaluated using a test-retest model. Through the use of percentages of agreement, analyses of variance, Pearson-product-moment correlations, and intra-class correlation coefficients it was determined that the CAS ensured perfect reliability and was free of variations in judgement and ensured perfect reproducibility of trial assessments.

\section{Summary}

According to Hunter and Funk (1984), the key muscle in the rehabilitation of the patellofemoral joint is the vastus medialis obliquus. "The vastus medialis is important in stabilizing the patella, it is a very sensitive index of knee derangement, as it is the first muscle to atrophy" (Roy \& Irvin, 1983, p. 298). The VMO is the only dynamic structure that can move the patella medially to a more advantageous position of function (Westfall \& Worrell, 1992).

Quadriceps strengthening is a common rehabilitation goal for patients with knee pathologies. Both open and closed kinetic chain exercises have been utilized to meet this goal. A current trend in many protocols is the use of closed kinetic chain exercises. Five studies have shown these exercises to cause less stress and strain to soft tissues in the knee (Blair \& DeLuca, 1991; Case et al., 1991; Graham et al., 1993; Paulos, Wnorowski, \& Beck, 1991; Yack et al., 1993).

One method used quite frequently to measure muscular activity is electromyography. This technique has allowed clinicians and investigators to 
further their knowledge of the function of muscles and how the nervous system controls muscles (Soderberg \& Cook, 1984). Currently there are few studies which have investigated EMG activity of the quadriceps muscle during closed kinetic chain exercises (Brask et al., 1984; Cook et al., 1992; Graham et al., 1993). To date, no studies exist which compare the EMG activity of the VMO during a wall squat in relation to foot position. This review of literature was intended to give an overview of the anatomical and functional characteristics of the VMO, open and closed kinetic chain rehabilitation, principles of EMG, specific EMG instrumentation, and to review the results of recent EMG studies of the lower extremity. 


\section{CHAPTER 3}

\section{METHODS}

This study compared the electromyographic activity of the vastus medialis obliquus with three variations of foot position: (a) feet in the neutral position, (b) feet externally rotated 20 degrees, and (c) feet internally rotated 20 degrees and in relation to gender during the eccentric portion of a 60 degree wall squat. This chapter presents the procedures that were used in this study and are presented in the following sections: (a) subjects, (b) instrumentation, (c) pilot study, (d) data collection, and (e) treatment of the data.

\section{Subjects}

Subjects who participated in this study were 26 healthy volunteers (13 males and 13 females) between the ages of 18-35 years, and were recruited by volunteer solicitation at San José State University during the spring semester 1994. Each subject gave informed consent in accordance with the guidelines established by San José State University's Institutional Review Board for Human Subjects (Appendix A). After giving the subjects the purpose of the study through written communication, the protocol for data collection and the opportunity to ask questions pertaining to this study, volunteers were asked to fill out an information sheet (Appendix B). Subjects were reviewed from the information given on the sheet and were required to meet the following criteria: (a) no history of a lower extremity injury in the last two months, with symptoms lasting longer than three days; (b) no involvement in a lower extremity weight 
lifting program exceeding two days per week; (c) ability to perform a wall squat with feet in three different positions.

\section{Instrumentation}

The EMG data were recorded using the Orion Model 8600 Biofeedback System $^{\circledR}$ (Self Regulation Systems, 14770 NE 95th, Redmond, WA 98052).

This system used a modality board that monitored EMG response and displayed feedback response to muscle tension. The EMG modality assembly consisted of an electronic circuit designed to be inserted into the Orion $8600^{\circ}$ chassis. The chassis provided electrical isolation between the power source and the probe. The modality performed bandpass filtering and was set at 100$200 \mathrm{Hertz}(\mathrm{Hz})$ (selectable from 100-1000 Hz). It also performed absolute rootmean-square (RMS) value signal conditioning of the EMG signal. The high pass filter slope of the modality board was $20 \mathrm{~dB} /$ Octave. A special $60 \mathrm{~Hz}$ "notch" filter was used to reject powerline interference generated by appliances, electrical cables, etc., in the proximity of the modality. The cable assembly consisted of a 10-inch length of plasticized, vinyl-jacketed, shielded leadwire with disposable, snap-type active electrodes. The sensitivity resolution was set at 100 microvolts (UV). A Movement-Over-Time (MOT) feedback cartridge was used to set Orion display data. The display was a cartesian graph with the $x$ - and $y$-axis representing time and magnitude, respectively. A standard Magnavox red-blue-green (RGB) color monitor and a Epson RX-80 dot matrix printer were used.

A Counselor ${ }^{\circledR}$-Borg ${ }^{\circledR}$ (2107 Kishwaukee Street, Rockford, IL 6110479093) digital scale was used to weigh the subjects. The scale was calibrated 
to measure within $1 \%$ of exact body weight. A standard six inch plastic goniometer was used to measure knee flexion to sixty degrees following the principles outlined by the American Academy of Orthopaedic Surgeons (1965).

To provide the subject with feedback to control the amount of knee flexion, an adjustable four foot by two foot "squat limiter" was constructed of peg board and plywood (Figure 3.1). A two-foot by five and one half-inch adjustable bench protruded perpendicular to the front of the peg board. The entire apparatus was attached to the wall with a five inch strip of Velcro ${ }^{\odot}$.

Figure 3.1: Squat Limiter

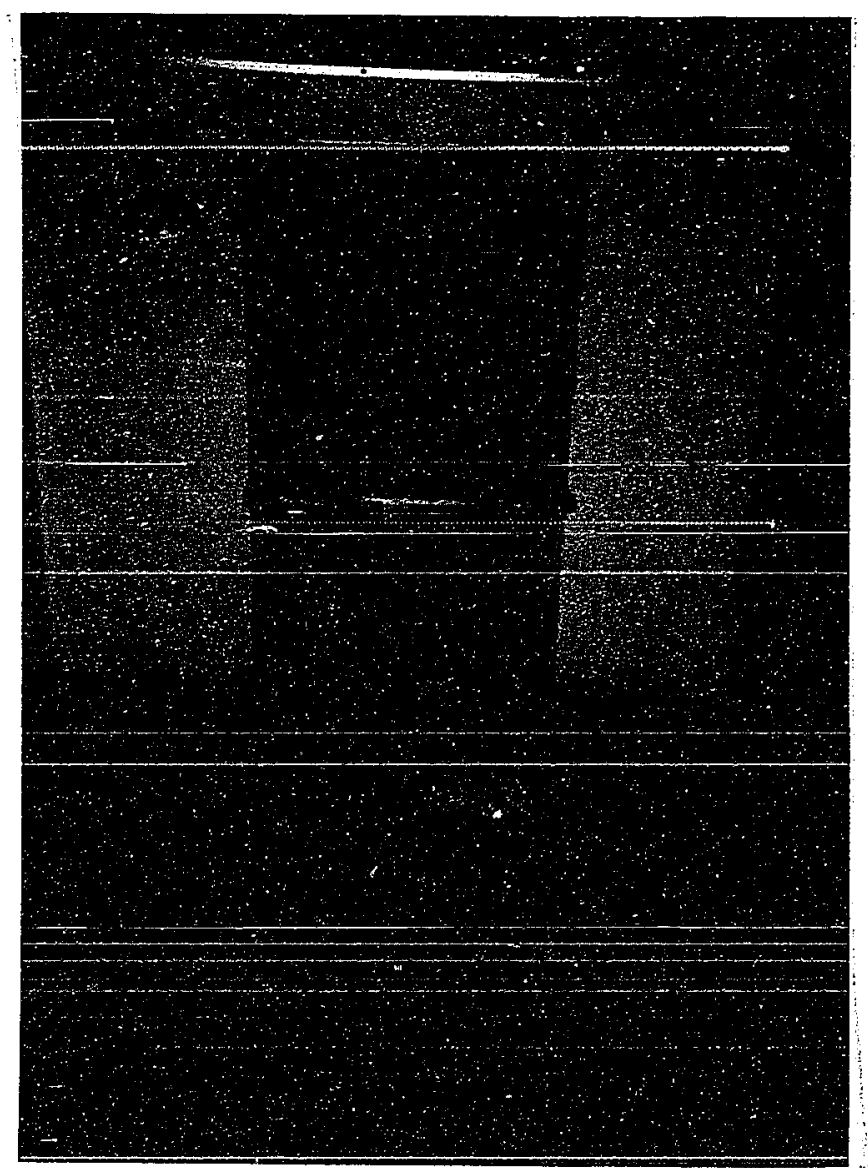


A 32- by 20-inch piece of matte board was used to construct a template with adjustable footprints on which the subjects stood to maintain the proper foot positioning throughout the experiment (Figure 3.2). The footprints were adjusted for each subject to be shoulder width apart. Appropriate lines were drawn on the feet to provide the subjects with a visual cue. One line was drawn which bisected the heel and the second toe, as this toe is considered to be the midpoint of the foot (Magee, 1987, p. 317). Two lines were drawn at 20 degree angies from the center line. The template was placed six inches in front of the squat-limiter and was stabilized to the floor by a five inch strip of Velcro ${ }^{\odot}$.

\section{Figure 3.2: Foot Template}

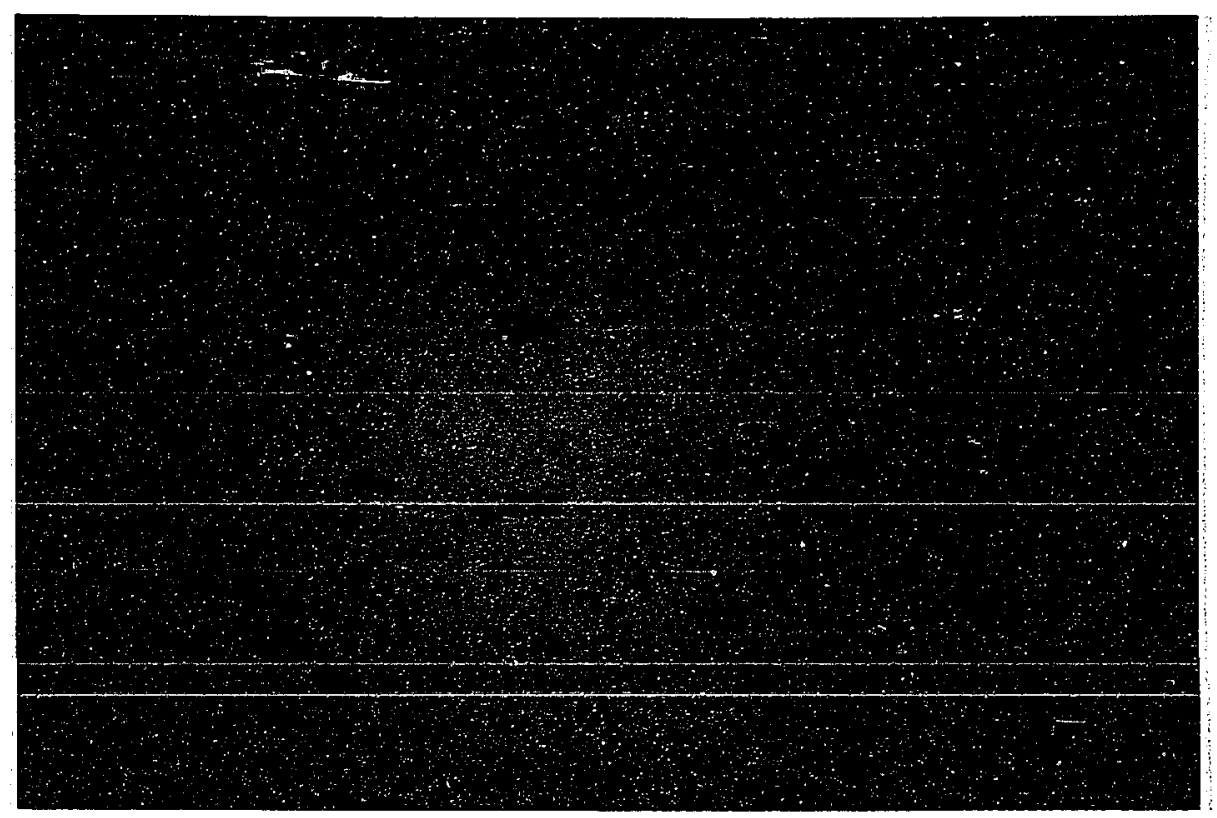

Standard cast-iron dumbbells in five pound increments were used in the study. Subjects wore weight lifting gloves during the experiment for comfort. 


\section{Pilot Study}

A pilot study was conducted to assure measurement efficiency and expertise prior to the beginning of the main study. Five subjects ( 3 males and 2 females) between the ages of 25-34, who qualified for participation by clearing the previously mentioned criteria, were utilized. Pilot study demographics are reported in Appendix $E$. Each subject gave informed consent in accordance with University policy and entered the testing room. The questionnaire was completed and the subject was aliowed to ask questions pertaining to the study. Each subject was then weighed on the digital scale. Mean body weight for the males was 175.3 pounds. Mean body weight for the females was 146.5 pounds.

Data were collected only on the dominant leg. Dominance was established using a kicking test. This test was performed by having the subject approach and kick (with the preferred leg) a ball that was placed on a designated spot on the floor in the middle of the testing room. The leg that kicked the ball was considered the dominant leg (Wong, 1984). In the pilot study, all five subjects were right leg dominant. The squats and foot positions were then demonstrated to each subject by the researcher and they in turn performed the exercise themselves to ensure proper technique. To keep foot position constant, the subjects were asked to place their feet (with shoes on) over the adjustable feet and line up their second toe with the lines which were drawn on the template.

Each subject's skin was prepared by shaving excess hair from the area over the VMO insertion and over the proximal tibial shaft just below the tibial tuberosity. Skin impedence was reduced by removing oil and superficial 
epithelia with a $70 \%$ isopropyl alcohol swab. Active surface electrodes were then positioned by the researcher. The ground electrode was placed on the subject's anterior tibial shaft prior to the placement of the two active electrodes in order to reduce electrostatic discharge (SRS, Inc., 1984). The active electrode location was over the belly of the VMO (lower one third of the vastus medialis) with the electrodes located in the longitudinal direction of the muscle fibers (Figure 3.3). The center of the VMO muscle belly was visually located during an isometric contraction of the quadriceps muscle. The cables were then taped $\left(3 M^{\circledR}\right.$ paper tape) to the subject to prevent the sensors from being pulled out of position.

Figure 3.3: Electrode Placement

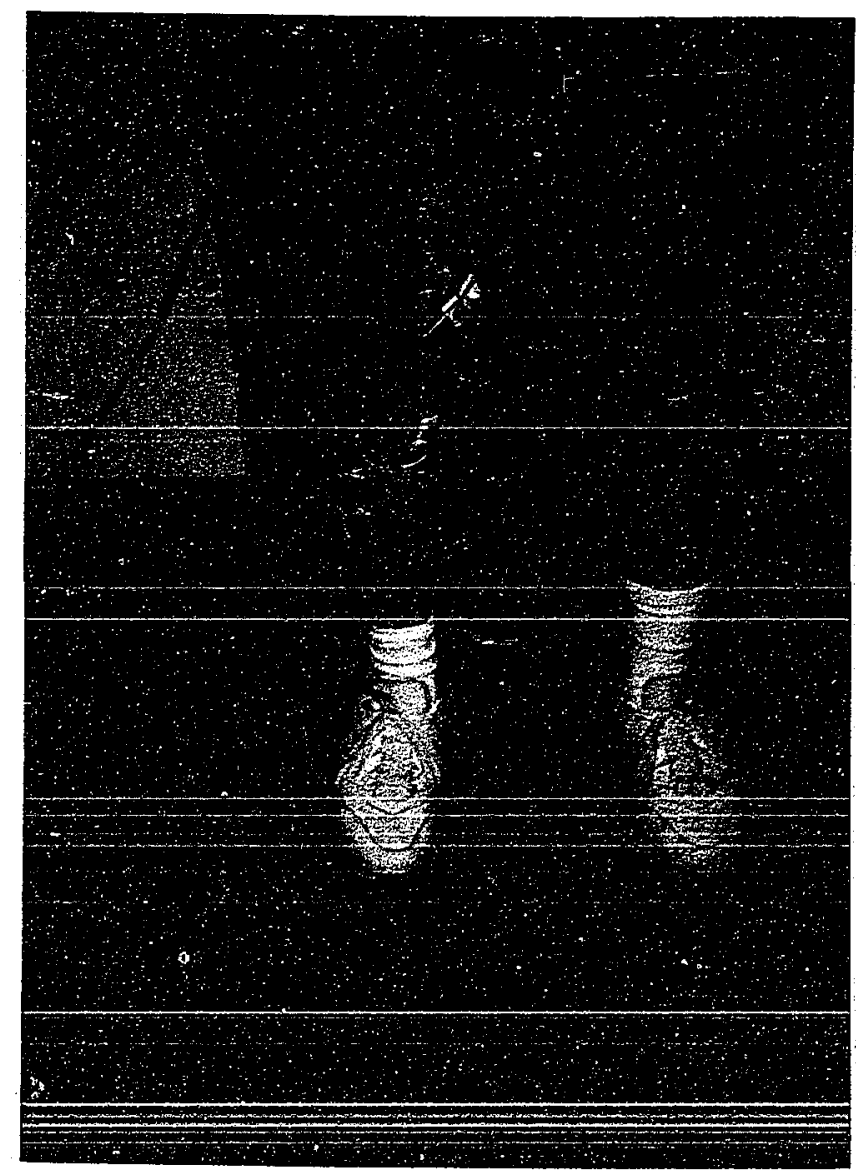


A set of fifteen squat repetitions was recorded for each subject in a specific foot position, at a given intensity level. Three sets, one at each foot position, made up one trial. Three trials, one at each intensity level, were recorded for each subject. A minute and a half rest period was given between sets and a four minute rest period was given between trials to limit the fatigue factor. The rate of the exercise was controlled by a tape recorded message repeating "down, up, down, up..." so the subject would squat one time every two seconds.

Intensity of the exercise was controlled by holding dumbbells weighing approximately 20,30 and 40 percent of the subject's body weight during the testing session. The dumbbells were held in front of the subject's body and were allowed to rest upon the upper thighs. The weight intensity and the three foot positions were randomly assigned (Appendix $C$ ). The weight that provided the most VMO activity and produced the least strain for the subject was used as the criteria for the actual study.

The subject was instructed to maintain the trunk in an upright position by keeping the back flat against the apparatus, flex the knees until their gluteals hit the bench (sixty degrees of knee flexion), then return to the fully extended position. The subject performed the wall squat with the feet in three different positions: feet neutral, externally rotated 20 degrees, and internally rotated 20 degrees. Subjects maintained proper foot position throughout the entire experiment by placing their feet on the matte board template. Descriptive statistics were used to determine the mean age, body weight, and peak EMG values of the subjects. 


\section{Pilot Study Results}

Due to the small sample size, only descriptive statistics were used to analyze the data. It was determined, by examining the group peak eccentric EMG means, that the amount of weight that promoted the most eccentric activity from the VMO was 30 percent of the body weight. This intensity was used throughout the main study.

The foot position which recruited the most eccentric VMO muscle activity (while holding 30 percent body weight) was external rotation, with an EMG peak value of 74.1 microvolts ( $(\mathrm{V})$. The second highest EMG peak value was 73.8 UV for internal rotation, and neutral was lowest with $72.4 \mathrm{uV}$. The group peak eccentric EMG values for the pilot study can be found in Table 3.1.

Table 3.1: Group Peak Eccentric EMG Values (Microvolts) from Pilot Study

\begin{tabular}{|c|c|c|c|c|}
\hline INTENSITY & NEUTRAL & EXT.ROT. & INT. ROT. & $\begin{array}{c}\text { INTENSITY } \\
\text { MEAN }\end{array}$ \\
\hline $20 \%$ & 67.8 & 58.8 & 64.1 & 63.6 \\
\hline $30 \%$ & 72.4 & 74.1 & 73.8 & 73.4 \\
\hline $40 \%$ & 64.3 & 68.8 & 73.0 & 68.7 \\
\hline $\begin{array}{c}\text { FOOT } \\
\text { POSITION } \\
\text { MEAN }\end{array}$ & 68.2 & 67.2 & 70.3 & \\
\hline
\end{tabular}




\section{Data Collection}

After describing the study to the subjects and giving them an opportunity to ask questions, twenty-six subjects read and signed a human subjects informed consent form in accordance with University policy. Subjects then completed an information sheet regarding their age, gender, and injury history prior to their test session. Main study demographics are reported in Appendix F.

Subjects were weighed, tested for leg dominance, squat and foot positioning was demonstrated and repeated, and the skin was preped for electrode placement using the same protocol as the pilot study. Subjects performed the wall squat while holding dumbbells weighing 30 percent of their body weight, as determined by the pilot study.

It was determined from the pilot study that instead of having the subject perform one set of fifteen continuous repetitions of the wall squat, the subject needed to perform fifteen separate trials of the wall squat so data could be recorded for each repetition. This method allowed the computer to give fifteen separate peak eccentric values instead of just one mean peak value (an average of both the eccentric and concentric, high and low, peaks).

The subject was provided auditory and visual cues while performing the wall squats by watching the computer screen of the Orion ${ }^{\odot}$. A "beep" was sounded right before the words "work" and "rest" appeared on the screen. The word "work" appeared for two seconds and then the word "rest" appeared for one second. As soon as the subject observed "work" disappear from the screen, he/she performed the wall squat. Practice trials were done by each subject until they feit comfortable with the timing. A one second inter-repetition rest period was allowed so the computer could record the peak, eccentric value 
for each repetition. Fifteen trials at each of the three foot positions were recorded for each subject. Foot position order was again randomly assigned by the researcher (Appendix D).

\section{Treatment of the Data}

The dependent variable assessed was the EMG activity of the VMO during the eccentric portion of a wall squat. The independent variables investigated were gender and foot positions. The mean, standard deviation, and the low and high EMG values for VMO activity were recorded for each subject. Group means and group standard deviations were tabulated using the Statistical Package for the Social Sciences (SPSS) (version 3.0) computer program. The mean difference between gender and EMG activity of the VMO was analyzed utilizing a two-way repeated measures analysis of variance (ANOVA) with repeated measures of one variable (foot position). The two-way ANOVA was tabulated by the Statistics by Finesse program. If significant differences were found, then a Scheffé post hoc analysis will be employed to determine the location of significant differences. The level of significance was set at .05 . 


\section{CHAPTER 4}

\section{ANALYSIS AND DISCUSSION OF DATA}

This study compared the eccentric EMG activity of the vastus medialis obliquus during a wall squat with the feet in three different positions. The problems for this study were: 1) to determine if there was a significant difference in eccentric VMO activity while performing the wall squat with three different foot positions, 2) to determine if there was a significant difference between males and females in eccentric VMO activity while performing the wall squat, and 3) to determine if there was an interaction between eccentric VMO activity with the three foot positions and gender.

It was determined that the protocol for the main study had to be slightly changed in order to fully utilize the statistical summaries produced by the Orion $8600^{\circ}$ when in the tabular mode. The subject had two seconds to perform one wall squat and then a one second rest period. This rest period enabled the computer to record each high and low peak of the EMG recording. For each subject, 15 separate peak values were recorded.

This chapter presents the results of this study in the following sections:

(a) demographics for the subjects, (b) validity and reliability, (c) main study results, and (d) discussion.

\section{Demographics for the Subjects}

The study included 26 subjects ( 13 males and 13 females), age $27.8 \pm$ 5.29 years with a mean body weight of $155.6 \pm 25.60$ pounds. Males ranged in age from $18-34$ (mean age $=27.9 \pm 4.69$ ) with a body weight that ranged from 
$144-200$ (mean body weight $=171.6 \pm 18.21$ pounds). Females ranged in age from $18-35$ (mean age $=27.8 \pm 6.03$ ) with a body weight that ranged from 91 174 pounds (mean body weight $=139.6 \pm 21.89$ pounds). Among the males, 8 were right leg dominant $(62 \%)$ and 5 were left leg dominant (38\%). Among the females, 12 were right leg dominant (92\%) and 1 was left leg dominant (8\%). Mean age, body weight and distribution of dominant lower extremity for the group can be found in Table 4.1.

Table 4.1: Mean Age, Body Weight and Distribution of Dominant Lower Extremities for Female and Male Subjects

\begin{tabular}{lcc}
\hline & Females & Males \\
\cline { 2 - 3 } Subject Number $(\mathrm{N})$ & 13 & 13 \\
Mean Age (years) & $27.8(18-35)$ & $27.9(18-34)$ \\
Mean Body Weight (pounds) & $139.6(91-174)$ & $171.6(144-200)$ \\
Right Leg Dominance (N) & 12 & 8 \\
Percentage of Right Leg Dominance & $92 \%$ & $62 \%$ \\
Left Leg Dominance (N) & 1 & 5 \\
Percentage of Left Leg Dominance & $8 \%$ & $38 \%$ \\
& & \\
\hline
\end{tabular}

\section{Validity and Reliability of Main Study}

Validity of EMG as a testing tool is well established as was explained in Chapter 2. Reliability of a study is dependent upon the researcher's ability to obtain a strong EMG signal. The methodology used in this study attempted to increase the reliability as was discussed in Chapter 2 . There were two different 
aspects of reliability the researcher observed. The reliability of the study, which was assessed qualitatively, and the reliability of the data, which was assessed quantitatively.

The reliability of this study was increased by following the four recommendations made by Turker (1993) in minimizing distortion. The first, taping of the surface electrodes to the skin; second, using the shortest possible leads; third, using active electrodes; fourth, placing the amplifier within $10 \mathrm{~cm}$ of the recording electrodes. The reliability was further increased by minimizing electrical noise by: (a) using active electrodes, (b) using bipolar recording technique, (c) grounding the subjects, and (d) using short leads (Turker, 1993).

The reliability of the data was done quantitatively by calculating an intraclass $R$ coefficient. The intraclass $R$ coefficient should be greater or equal to .70 to reflect good reliability. The intraclass $R$ coefficients were calculated for the three dependent variables in this study and were neutral $=.93$, external rotation $=.89$, and internal rotation $=.93$. ANOVA tables can be found in Appendix $\mathrm{H}$.

\section{Main Study Results}

The means and standard deviations of the EMG amplitudes for VMO activity were calculated for the male and female groups and are presented in Table 4.2. 
Table 4.2: Male and Female Means and Standard Deviations of Peak Eccentric EMG Values (Microvolts) for Three Foot Positions

\begin{tabular}{|c|c|c|c|c|c|c|}
\hline \multirow[b]{2}{*}{ Foot Position } & \multicolumn{2}{|c|}{ Male $(n=13)$} & \multicolumn{2}{|c|}{ Female $(n=13)$} & \multicolumn{2}{|c|}{ Group $(n=26)$} \\
\hline & Mean & St. Dev. & Mean & St. Dev. & Mean & St. Dev \\
\hline Neutral & 29.6 & 12.1 & 22.1 & 12.4 & 25.9 & 12.6 \\
\hline External Rot. & 28.7 & 14.5 & 24.2 & 16.0 & 26.5 & 15.2 \\
\hline Internal Rot. & 28.7 & 12.7 & 25.0 & 18.5 & 26.9 & 15.7 \\
\hline Group Mean & 29.0 & 12.8 & 23.8 & 15.5 & & \\
\hline
\end{tabular}

The group mean peak eccentric EMG values for the wall squat with foot position of neutral was $25.9 \pm 12.6 \mathrm{uV}$, external rotation was $26.5 \pm 15.2 \mathrm{uV}$, and internal rotation was $26.9 \pm 15.7$ uV.

The mean peak eccentric EMG activity level for the males for all three foot positions was $29.0 \pm 12.8 \mathrm{uV}$ while the females had a mean EMG value of 23.8 $\pm 15.5 \mathrm{uV}$. Although male mean peak eccentric EMG values were greater than the females, the difference was not statistically significant.

The foot position which had the highest mean peak eccentric EMG value for the male subjects was neutral, with a mean EMG value of $29.6 \pm 12.1 \mathrm{uV}$. The mean EMG value for internal rotation was $28.7 \pm 12.7 \mathrm{uV}$. The mean EMG value for external rotation was $28.7 \pm 14.5 \mathrm{uV}$.

The foot position which had the highest value for females was internal rotation, with a mean peak eccentric EMG value of $25.0 \pm 18.5 \mathrm{uV}$. The foot position which had the second highest mean peak eccentric EMG value was external rotation with $24.2 \pm 16.0 \mathrm{uV}$. The neutral foot position with the lowest peak eccentric EMG value for the females with $22.1 \pm 12.4 \mathrm{uV}$. 
A two-way analysis of variance (ANOVA) with repeated measures on one independent variable (foot position) were used to analyze the main effects of gender and foot position. The research design was a three (neutral, external rotation, internal rotation) by two (male and female), factorial design (Thomas and Nelson, 1985). Table 4.3 presents the results of the two-way ANOVA with repeated measures on one independent variable (foot position).

Table 4.3: Two-Way ANOVA with Repeated Measures on Foot Position in Relation to Gender

\begin{tabular}{lrrrrr}
\hline Source & DF & Sum of Squares & Mean Square & F-Ratio & p-Value \\
\hline Between Subj. & 25 & 14766.414 & & & \\
Groups & 1 & 535.109 & 535.109 & 0.902 & .3516 \\
Error & 24 & 14231.306 & 592.971 & & \\
Within Subj. & 52 & 1081.660 & & & \\
Treatments & 2 & 13.280 & 6.640 & 0.313 & .7327 \\
Interaction & 2 & 50.147 & 25.073 & 1.182 & .3154 \\
Error & 48 & 1018.233 & 21.213 & & \\
Total & 77 & 15848.074 & & & \\
\hline
\end{tabular}

As demonstrated in Table 4.3, the main effect of eccentric VMO activity during the wall squat with three different foot positions was not significant $(E(2,48)=0.313)$. The main effect of eccentric VMO activity during the wall squat for gender was not significant $(E(1,24)=0.902)$. The interaction between gender and foot position was also not significant $(E(\varepsilon, 48)=1.182)$. Therefore, based on the statistical analysis, the null hypotheses were accepted. A Scheffé 
post hoc analysis was not necessary due to the non-significant findings.

The practical significance of the data was calculated. This tells the proportion of total variance due to the "treatment". This value can be interpreted as the strength of the relationship between the independent and dependent variable. The value of atea $\left(w^{2}\right)$ should equal .50 or greater to show practical significance. This study showed high practical significance for each foot position with values of .87 for neutral, .81 for external rotation, and .87 for internal rotation. Had the sample size been larger, statistical significance may have been found. Practical significance calculations can be found in Appendix K.

\section{Discussion}

Parametric statistics were used to analyze the data, even though the normality assumption was not met. Normality describes the distribution of the dependent variable at each level of the independent variable. With this in mind, the results of this study have a slightly inflated Type I error; that is, the alpha level may be larger than initially intended (.07-.09 instead of .05).

Three hypotheses were tested in this study. The first hypothesis stated there would be no difference in eccentric VMO activity during the wall squat with three different foot positions. The quantification of differences in EMG amplitudes between the three foot positions may have been dependent upon the speed of movement when performing the wall squat. Sczepanski et al. (1991) found there to be a significant difference in VMO activity between the angular velocities of 60 degrees per second and 120 degrees per second. In an attempt to control the speed of movement (one squat per two second work 
period), it was still felt by the researcher that there had been some inconsistency which may have influenced the data.

No studies have investigated the relationship between VMO activity in relation to foot position while performing a closed kinetic chain exercise. One study by Hanten and Schulthies (1990) studied an open kinetic chain exercise with an isometric contraction and medial tibial rotation. Results of this study are in agreement with Hanten and Schulthies with respect to non-significant differences with medial tibial rotation. In the study by Yack et al. (1993), subjects performed the parallel squat while keeping their backs straight, their feet in 20 degrees of external rotation and shoulder width apart. However, only anterior tibial displacement (ATD) was studied in this investigation. The parallel squat was shown to produce less ATD than the knee extension (open kinetic chain) exercise. In the study by Graham et al. (1993), no mention of the foot position the subjects used during the uni-lateral squat was mentioned.

The second hypothesis stated there would be no difference in eccentric VMO activity between males and females. The gender variable was studied because research shows that the female population experiences a greater rate of patellofemoral pathologies than the male population. Moss, DeVita and Dawson (1992) stated that anterior knee pain occurs most commonly in adolescent females. Women tend to develop patella-related pain for biomechanical reasons (ie: increased $Q$-angle because the female pelvis is broader than the male pelvis).

The third hypothesis stated there would be no interaction between gender and foot position while performing the wall squat. No interaction was expected since the other two hypotheses were found to be non-significant. This 
study is in agreement with Karst and Jewett (1993) with respect to the nonsignificant findings between male and female subgroups of their sample.

The methodology chosen for this study was based upon the assumption that the amplitudes achieved performing the wall squat were indicative of strength levels expected as a result of training to isolate the VMO. That assumption appears to be justified for several reasons. First, data for each subject were collected in a single session in order to ensure that electrode placement and amplification were unchanged across foot positions. Second, the study's reliability was increased by attempting to negate the effects of fatigue, learning, or changes in skin-electrode contact. Third, the specific exercise used in this study is commonly prescribed (closed kinetic chain exercise) to strengthen the quadriceps during knee rehabilitation.

In this study, only the eccentric phase of the contraction was examined because it represents more functional movement (Gray, 1993). Functional rehabilitation is a critical component in the treatment of lower extremity injuries and an accelerated return to activities for daily living. Even though this particular exercise is not as functional as some other closed kinetic chain exercises, it is a good way to maximize VMO recruitment while minimizing vastus lateralis activity (Tremain, 1993).

Because these results were obtained by studying subjects with asymptomatic knees, rather than subjects with knee pathology, caution is warranted in generalizing these findings to patient populations. The study by Souza and Gross (1991) compared EMG data of the VMO to the vastus lateralis (VL) between healthy patients and patients with patellofemoral pain. There were significant differences found between these groups and it was suggested 
that patients with patellofemoral pain may differ from healthy individuals with regard to VMO:VL activation patterns. It should be noted, however, that when Soderberg and Cook (1987) investigated the difference between quad sets and SLR's in healthy subjects and subjects with knee pathology there were no statistically significant differences found between the groups.

There is widespread agreement that conservative treatment of patients with knee pathologies should include active exercise aimed at strengthening the VMO in particular. This study has implications for rehabilitation programs even though the results were non-significant. The results of this study do not support the suggestion that varying foot position will preferentially activate the VMO when performed in conjunction with the wall squat. Clinicians need not waste their time or the patient's time by having the patient perform multiple repetitions of the wall squat with their feet in different positions. Any one of these positions, neutral, external or internal rotation, should be sufficient in recruiting the fibers of the VMO. 


\title{
CHAPTER 5
}

\section{SUMMARY, CONCLUSIONS AND RECOMMENDATIONS}

\begin{abstract}
Summary
This study compared the EMG activity of the VMO during the eccentric portion of the wall squat with the feet in three different positions and in relation o gender. Following is a summary of procedures and findings, conclusions, and recommendations for further study.
\end{abstract}

\section{Procedures}

Five subjects, three males and two females, were used for a pilot study to assure measurement efficiency and expertise prior to the beginning of the actual study. All participants performed fifteen repetitions of a wall squat to 60 degrees of knee flexion with their feet in three different positions: neutral, external rotation, and internal rotation. EMG data were acquired using the Orion 8600 Biofeedback System $^{\circledR}$. Surface electrodes were used and EMG data were recorded during the exercise for each foot position using the subject's dominant leg. Intensity of the exercise was controlled by having the subjects hold dumbbells weighing 20,30 , and 40 percent of their body weight. Intensity and foot position were randomly assigned by the researcher. The weight which provided the most VMO activity and the least strain for the subjects was used as the criteria for the actual study.

Twenty-six healthy volunteers, 13 males and 13 females, which ranged in age from 18-35 years served as subjects in the main study. Intensity of the exercise was controlled by having the subjects hold dumbbells weighing 30 
percent of their body weight, as this was the weight determined by the pilot study to be the criteria weight. Foot position was again randomly assigned by the researcher. Only the eccentric portion of the wall squat was analyzed for interpretation.

\section{Findings}

It was determined from the two-way ANOVA table that there were no statistically significant differences in eccentric VMO activity during the wall squat with feet in three different positions in relation to gender. It was determined from the intraclass $R$ coefficient that the data had good reliability. The study was also shown to be practically significant.

\section{Conclusions}

Based upon the statistical findings of this study, within limitations and delimitations of the study, the data do not support the theory of varying foot positions to isolate the VMO while performing the wall squat, whether the patient is male or female.

\section{Recommendations for Further Study}

From the results presented in this study, the following recommendations for future research are suggested:

1. Because this study involved only healthy subjects, research should be undertaken to investigate the VMO activity of patients with knee pathologies specifically patellofemoral dysfunction, when performing the wall squat with feet in three different positions. 
2. Increase the size of the sample so the normality assumption for parametric statistics can be met. Since there were statistically non-significant differences in muscular activity between males and females in relation to foot positions, maybe a larger sample size would create different results.

3. Further research is needed to study closed kinetic chain exercises that target the VMO. For instance, research involving the lateral step-up should be initiated since this exercise has been referenced to increase VMO activity more than other closed kinetic chain exercises studied (Brask et al., 1984; Cook et al., 1992; Graham et al., 1993).

4. Further research on closed kinetic chain exercises that target the VMO (ie: step-ups, shuttle, leg press, step-down, etc.) should be done while varying foot position.

5. Peak concentric contractions of the wall squat should be examined with the EMG and compared to the results of this study. This would be important to study because rehabilitation should concentrate on strengthening the patient's knee when going up as well as going down.

6. Intra-muscular wire electrodes should be used instead of surface electrodes. Intra-muscular electrodes increase the sensitivity of the EMG signal and the frequency spectrum of motor unit potentials is much higher than that of the surface EMG (Turker, 1994). Intra-muscular electrodes would not be allowed by this Human Subjects Committee due to the invasiveness of the technique.

7. Additional research should investigate different knee flexion angles during the wall squat to see if VMO muscular activity is increased at certain ranges of motion. 
8. Additional research should investigate the wall squat with an accompanying ball squeeze to determine if an adduction component would increase VMO activity. Studies have shown that during open kinetic chain exercises, adduction aids in activating the VMO during knee extension (Hanten \& Schulthies, 1990). 
REFERENCES

American Academy of Orthopaedic Surgeons. (1965). Joint motion: Method of measuring and recording (pp.66-67). Chicago, IL.

Basmajian, J.V., \& DeLuca, C.J. (1985). Muscles alive: Their functions revealed by electromyography (5th Ed.). Baltimore, MD: Williams \& Williams.

Blair, D.F., \& Wills, R.P. (1991). Rapid rehabilitation following anterior cruciate ligament reconstruction. Journal of Athletic Training, 26, 32-43.

Brask, B., Lueke, R.H., \& Soderberg, G.L. (1984). Electromyograpic analysis of selected muscles during the lateral step-up exercise. Physical Therapy, 64(3), 324-329.

Bunton, E.E., Pitney, W.A., Kane, A.W., \& Cappaert, T.A. (1993). The role of limb torque, muscle action and proprioception during closed kinetic chain rehabilitation of the lower extremity. Journal of Athletic Training, 28(1), 1020.

Case, J.G., DePalma, B.F., \& Zelko, R.R. (1991). Knee rehabilitation following anterior cruciate ligament repair/reconstruction: An update. Journal of Athletic Training, 26, 22-31.

Chandler, T.J. \& Stone, M.H. (1991). The squat exercise in athletic conditioning: A position statement and review of the literature. National Strength and Conditioning Journal, 13(5), 51-60.

Cook, T.M., Zimmerman, C.L., Lux, K.M., Neubrand, C.M., \& Nicholson, T.D. (1992). EMG comparison of lateral step-up and stepping machine exercise. Journal of Orthopaedic and Sports Physical Therapy, 16(3), 108-113.

Crouch, J.E. (1985). Functional human anatomy (4th Ed.). Philadelphia: Lea \& Febiger.

DiFabio, R.P. (1987). Reliability of computerized surface electromyography for determining the onset of muscle activity. Physical Therapy, 67(1), 43-48.

Fahey, T.D. (1986). Athletic training: Principles and practice. Palo Alto, CA: Mayfield.

Francis, R.S. \& Scott, D.E. (1974). Hypertrophy of the vastus medialis in knee extension. Physical Therapy, 54(10), 1066-1070.

Graham, V.L., Gehlsen, G.M., \& Edwards, J.A. (1993). Electromyographic evaluation of closed and open chain knee rehabilitation exercises. Journal of Athletic Training, 28(1), 23-30. 
Gray, G. W. (1993, October). Chain Reaction: Successful strategies for closed chain and open chain testing and rehabilitation. Material presented at the Chain Reaction seminar in San Diego, CA.

Hanten, G.M., \& Schulthies, S.S. (1990). Exercise effect on electromyographic activity of the vastus medialis oblique and vastus lateralis muscles. Physical Therapy, $\underline{70}$ (9), 561-565.

Hunter, L.Y. \& Funk, F.J. (Eds.). (1984). Rehabilitation of the injured knee. St. Louis: C.V. Mosby.

Karst, G.M., \& Jewett, P.D. (1993). Electromyographic analysis of exercises proposed for differential activation of medial and lateral quadriceps femoris muscle contractions. Physical Therapy, 73(5), 286-299.

Lenman, J.A.R. \& Ritchie, A.E. (1983). Clinical electromyography (3rd Ed.). London: Pitman Books Limited.

LeVeau, B.F. \& Rogers, C. (1980). Selective training of the vastus medialis muscle using EMG biofeedback. Physical Therapy, 60(11),1410-1415.

Magee, D.J. (1987). Orthopedic physical assessment, Philadelphia: W.B. Saunders.

Merten, T., \& Potteiger, J.A. (1991). Strength training: Proper techniques for the big three. Journal of Athletic Training, 26, 295-309.

Morris, W. (Ed.). (1981). The American Heritage Dictionary of the American Language, Boston: Houghton Mifflin Company.

Moss, R.I., DeVita, P., \& Dawson, M.L. (1992). A biomechanical analysis of patellofemoral stress syndrome, Journal of Athletic Training, 27(1), 64-69.

Nelson, R.M. \& Currier, D.P. (Ed.). (1987). Clinical electrotherapy. Los Altos, CA:Appleton \& Lange.

Nicholas, J.A. \& Hershman, E.B. (Eds.). (1986). The lower extremity and spine in sports medicine (Vol. 1), St. Louis: C.V. Mosby.

Palmittier, R.A., An, K., Scott, S.G., \& Chao, E.Y.S. (1991). Kinetic chain exercise in knee rehabilitation. Sports Medicine, 11(6), 402-413.

Paulos, L., Rusche, K., Johnson, C., \& Noyes, F.R. (1980). Patellar malalignment: A treatment rationale. Physical Therapy, $\underline{60}$ (12), 1624-1632.

Paulos, L.E., Wnorowski, D.C., \& Beck, C.L. (1991). Rehabilitation following knee surgery: Recommendations. Sports Medicine, 11(4), 257-275. 
Pevsner, D.N., Johnson, J.R.G., \& Blazina, M.E. (1979). The patellofemoral joint and its implications in the rehabilitation of the knee. Physical Tharapy, $\underline{59}(7), 869-874$

Prentice, W.E. (1994). Rehabilitation techniques in sports medicine (2nd Ed.). St. Louis: Mosby.

Reynolds, L., Levin, T.A., Medeiros, J.M., Adler, N.S., \& Hallum, A. (1983). EMG activity of the vastus medialis oblique and the vastus lateralis in their role in patellar alignment. American Journal of Physical Medicine, 62(2), 61-70.

Roy, S. \& Irvin, R. (1983). Sports medicine: Prevention, evaluation, management, and rehabilitation, New Jersey: Prentice-Hall.

Sczepanski, T.L., Gross, M.T., Duncan, P.W., \& Chandler, J.M. (1991). Effect of contraction type, angular velocity, and arc of motion on VMO: VL EMG ratio. Journal of Orthopaedic and Sports Physical Therapy, 14(6), 256-262.

Soderberg, G.L., \& Cook, T.M. (1983). An electromyographic analysis of quadriceps femoris muscle setting and straight leg raising. Physical Therapy, 63(9), 1434-1438.

Soderberg, G.L., \& Cook, T.M. (1984). Electromyography in biomechanics. Physical Therapy, 64(12), 1813-1820.

Soderberg, G.L., Minor, S.D., Arnold, K., Henry, T., Chatterson, J.K., Poppe, D.R., \& Wall, C. (1987). Electromyographic analysis of knee exercises in healthy subjects and in patients with knee pathologies. Physical Therapy, 67, 1691-1696.

Souza, D.E., \& Gross, M.T. (1991). Comparison of vastus medialis obliquus: vastus lateralis muscle integrated electromyographic ratios between healthy subjects and patients with patellofemoral pain. Physical Therapy, 71(4), 310-320.

Thomas, C.L. (Ed). (1985). Taber's Cyclopedic Medical Dictionary. Fifteenth Edition. F.A. Davis Company, Philadelphia.

Thomas, J.R. and Nelson, J.K. (1985). Introduction to research in health, physical eduation, recreation, and dance. Human Kinetics:Champaign, IL.

Tremain, L.K. (1993, September). Vastus Medialis Obliquus (VMO) Protocol. Physical Therapy Products, pp. 12-13.

Turker, K.S. (1993). Electromyography: Some methodological problems and issues. Physical Therapy, 73(10), 57-69. 
Wallace, L.A., Mangine, R.E., \& Malone, T.R. (1990). The knee. In J.A. Gould (Ed.), Orthopaedic and Sports Physical Therapy (pp.323-345). St. Louis: C.V. Mosby.

Westfall, D.C., \& Worrell, T.W. (1992). Anterior knee pain syndrome: Role of the vastus medialis oblique. Journal of Sport Rehabilitation, 1 , 317-325.

Wild, J.J., Franklin, T.D., \& Woods, G.W. (1982). Patellar pain and quadriceps rehabilitation: An EMG study. The American Journal of Sports Medicine, 10(1), 12-15.

Wong, D.L., Glasheen-Wray, M., \& Andrews, L.F. (1984). Isokinetic evaluation of the ankle invertors and evertors. The Journal of Orthopaedic and Sports Physical Therapy, 5(5), 246-252.

Yack, H.J., Collins, C.E., \& Whieldon, T.J. (1993). Comparison of closed and open kinetic chain exercise in the anterior cruciate ligament-deficient knee. The American Journal of Sports Medicine, 21(1), 49-54. 
APPENDIX A CONSENT FORM

\section{AGREEMENT TO PARTICIPATE IN RESEARCH SAN JOSE STATE UNIVERSITY}

RESPONSIBLE INVESTIGATOR: Tiffiny Shellese Shay, A.T.,C.

TITLE OF PROTOCOL: Electromyographic Activity of the Vastus Medialis Obliquus During a Wall Squat in Relation to Gender and Three Foot Positions.

I have been asked to participate in a research study that is investigating the electromyographic activity of the vastus medialis obliquus during a wall squat in relation to gender and three foot positions. The results of this study should further our understanding of the effectiveness of closed kinetic chain exercises for quadriceps strengthening during knee rehabilitation.

I understand that:

1) I will be asked to perform a wall squat, which will require bending the knees approximately 60 degrees, with my feet in three different positions. I understand that I will be required to hold dumbbells which will weigh approximately 30 percent of my body weight while squatting. I understand that this will take place at San José State University and take approximately 15 minutes to complete.

2) The risks of this study are minimal, but may include: muscular soreness associated with the training session and a skin irritation from the adhesive backing which is on the electromyographic surface electrodes.

3) The possible benefits of this study to me are the further development of the base of scientific knowledge in the area of knee rehabilitation.

4) The results from this study may be published, but any information from this study that can be identified with me will remain confidential and will be disclosed only with my permission or as required by law.

5) Any question about my participation in this study will be answered by Tiffiny S. Shay, A.T.,C. at (408) 578-9980. Complaints about the procedures may be presented to Dr. Mike Huang, P.E.D., A.T.,C. (Thesis Advisor) at (408) 924-3019. For questions or complaints about research subject's rights, or 
in the event of research-related injury, contact Serena Stanford, Ph.D. (Associate Academic Vice President for Graduate Studies \& Research) at (408) $924-2480$.

6) my consent is given voluntarily without being coerced; I may refuse to participate in this study or in any part of this study, and I may withdraw at any time, without prejudice to my relations with SJSU.

7) I have received a copy of this consent form for my file.

I HAVE MADE A DECISION WHETHER OR NOT TO PARTICIPATE. MY SIGNATURE INDICATES THAT I HAVE READ THE INFORMATION PROVIDED ABOVE AND THAT I HAVE DECIDED TO PARTICIPATE.

Subject's Signature

Investigator's Signature
Date

Date 


\section{APPENDIX B} QUESTIONNAIRE

Dear subject:

Number

We are interested in determining which foot position will recruit more muscle activity in the vastus medialis obliquus during the wall squat. In order to successfully carry out this experiment a few questions must be answered.

Participation is completely voluntary. The questionnaire is completely anonymous. DO NOT PUT YOUR NAME ON IT. When you have completed only the top portion of the questionnaire a few simple tasks will need to be performed before we start. Thank you very much for you help.

AGE

GENDER

ARE YOU INVOLVED INA WEIGHT LIFING PROGRAM FOR YOUR LOWER EXTREMITY TWO OR MORE DAYS PER WEEK?

YES No

HAVE YOU HAD ANY LOWER EXTREMITY INUURIES (FOOT. ANKLE. KNEE OR HIP) INTHE LAST 2 MONTHS IN WHICH THE SYMPTOMS LASTED FOR MORE THAN 3 DAYS?

YES NO

SUBJECT CAN DEMONSTRATEA WALL SQUAT WITH: FEET NEUTRAL FEET EXTERNALLY ROTATED FEET INTERNALLY ROTATED

BODY WEIGHT WITH CLOTHES

WEIGHT SUBJECT WILL BE LIFIING DURING THE SQUATS: $\quad 30 \%$ OF B. W. $=$ LBS.

DOMINANT LEG : FOOT POSITIONS: (1) 
APPENDIX C

RANDOMLY CHOSEN FOOT POSITIONS \& WEIGHT LIFTED

\begin{tabular}{|c|c|c|c|c|}
\hline $\begin{array}{l}\text { SUB. \#1 } \\
\text { 1st Trial 20\% }\end{array}$ & $\begin{array}{l}\text { SUB. \#2 } \\
\text { 1st Trial } 20 \%\end{array}$ & $\begin{array}{l}\text { SUB. \#3 } \\
\text { 1st Trial } 40 \% \\
\end{array}$ & $\begin{array}{l}\text { SUB. } \# 4 \\
\text { 1st Trial } 20 \%\end{array}$ & $\begin{array}{c}\text { SUB. \#5 } \\
\text { 1st Trial } 40 \%\end{array}$ \\
\hline Set (1) $N$ & (1) ER & (1) IR & (1) IR & (1) $\mathrm{N}$ \\
\hline \multicolumn{5}{|c|}{ REST PERIOD OF $11 / 2$ MINUTES } \\
\hline Set (2) ER & (2) $\mathrm{N}$ & (2) $\mathrm{N}$ & (2) ER & (2) ER \\
\hline \multicolumn{5}{|c|}{ REST PERIOD OF $11 / 2$ MINUTES } \\
\hline Set (3) IR & (3) IR & (3) ER & (3) $\mathrm{N}$ & (3) IR \\
\hline \multicolumn{5}{|c|}{ REST PERIOD OF 4 MINUTES } \\
\hline 2nd Trial $30 \%$ & 2nd Trial $40 \%$ & 2nd Trial $30 \%$ & 2nd Trial $40 \%$ & 2nd Trial $30 \%$ \\
\hline Set (1) $N$ & (1) $N$ & (1) IR & (1) IR & (1) IR \\
\hline \multicolumn{5}{|c|}{ REST PERIOD OF $11 / 2$ MINUTES } \\
\hline Set (2) ER & (2) IR & (2) $\mathrm{N}$ & (2) $\mathrm{N}$ & (2) $\mathrm{N}$ \\
\hline \multicolumn{5}{|c|}{ REST PERIOD OF $11 / 2$ MINUTES } \\
\hline Set (3) IR & (3) ER & (3) ER & (3) ER & (3) ER \\
\hline \multicolumn{5}{|c|}{ REST PERIOD OF 4 MINUTES } \\
\hline 3rd Trial 40\% & 3rd Trial 30\% & 3 rd Trial $20^{\circ}$ & 3rd Trial $30 \%$ & 3rd Trial $20 \%$ \\
\hline Set (1) ER & (1) ER & (1) IR & (1) ER & (1) IR \\
\hline \multicolumn{5}{|c|}{ REST PERIOD OF 1 1/2 MINUTES } \\
\hline Set (2) $N$ & (2) $\mathrm{N}$ & (2) $\mathrm{N}$ & (2) $\mathrm{N}$ & (2) $\mathrm{ER}$ \\
\hline \multicolumn{5}{|c|}{ REST PERIOD OF $11 / 2$ MINUTES } \\
\hline Set (3) IR & (3) IR & (3) ER & (3) IR & (3) $\mathrm{N}$ \\
\hline
\end{tabular}


APPENDIX D

MAIN STUDY RANDOMLY CHOSEN FOOT POSITIONS

\begin{tabular}{|c|c|c|c|}
\hline SUBJECT & $\begin{array}{l}\text { FOOT POSITION } \\
\text { 1ST TRIAL }\end{array}$ & $\begin{array}{l}\text { FOOT POSITION } \\
\text { 2ND TRIAL }\end{array}$ & $\begin{array}{l}\text { FOOTPOSITION } \\
\text { 3RD TRIAL }\end{array}$ \\
\hline $\begin{array}{l}1 \\
2 \\
3 \\
4 \\
5 \\
6 \\
7 \\
8 \\
9 \\
10 \\
11 \\
12 \\
13 \\
14 \\
15 \\
16 \\
17 \\
18 \\
19 \\
20 \\
21 \\
22 \\
23 \\
24 \\
25 \\
26\end{array}$ & $\begin{array}{l}N \\
\mathbb{N} \\
\mathbb{R} \\
\mathbb{R} \\
N \\
\mathbb{R} \\
N \\
\text { ER } \\
\mathbb{R} \\
\text { ER } \\
\text { ER } \\
\text { ER } \\
N \\
\text { ER } \\
\text { ER } \\
N \\
N \\
\text { ER } \\
N \\
\mathbb{R} \\
\mathbb{R} \\
\text { ER } \\
\text { ER } \\
\mathbb{R} \\
\text { ER } \\
N \\
\text { ER }\end{array}$ & $\begin{array}{l}\mathbb{R} \\
N \\
N \\
\text { ER } \\
\text { ER } \\
\text { ER } \\
N \\
\text { R } \\
N \\
N \\
N \\
\mathbb{R} \\
\mathbb{R} \\
\mathbb{R} \\
N \\
\text { ER } \\
\text { ER } \\
N \\
\text { ER } \\
\text { ER } \\
N \\
N \\
N \\
N \\
N \\
N \\
\mathbb{R} \\
\mathbb{R}\end{array}$ & $\begin{array}{l}\text { ER } \\
\mathbb{R} \\
\text { ER } \\
\mathbb{R} \\
\mathbb{R} \\
\mathbb{R} \\
\mathbb{R} \\
\mathbb{R} \\
\mathbb{N} \\
\mathbb{R} \\
\mathbb{R} \\
\mathbb{R} \\
\mathbb{R} \\
\text { ER } \\
\mathbb{N} \\
\mathbb{R} \\
\mathbb{R} \\
\mathbb{R} \\
\mathbb{R} \\
\mathbb{R} \\
\mathbb{R} \\
\mathbb{N} \\
\mathbb{E R} \\
\mathbb{R} \\
\mathbb{R} \\
\mathbb{R} \\
\mathbb{R} \\
\mathbb{R} \\
\mathbb{R} \\
\mathbb{N}\end{array}$ \\
\hline
\end{tabular}

$\mathrm{N}=$ Neutral Foot Position

IR = Internal Rotation Foot Position

$E R=$ External Rotation Foot Position 
APPENDIX E

PILOT STUDY SUBJECT DEMOGRAPHICS

\begin{tabular}{ccccc}
\hline SUBJECT & AGE & GENDER & $\begin{array}{c}\text { BODY } \\
\text { WEIGHT } \\
\text { (lbs) }\end{array}$ & $\begin{array}{c}\text { DOMINANT } \\
\text { LEG }\end{array}$ \\
\hline 1 & 30 & $F$ & 157 & $R$ \\
2 & 30 & $M$ & $192^{-}$ & $R$ \\
3 & 34 & $F$ & 136 & $R$ \\
4 & 25 & $M$ & 162 & $R$ \\
5 & 30 & $M$ & 172 & $R$ \\
\hline
\end{tabular}


MAIN STUDY SUBJECT DEMOGRAPHICS

\begin{tabular}{|c|c|c|c|c|}
\hline SUBJECT & AGE & GENDER & $\begin{array}{c}\text { BODY } \\
\text { WEIGHT } \\
\text { (Ibs) }\end{array}$ & $\begin{array}{c}\text { DOMINANT } \\
\text { LEG }\end{array}$ \\
\hline 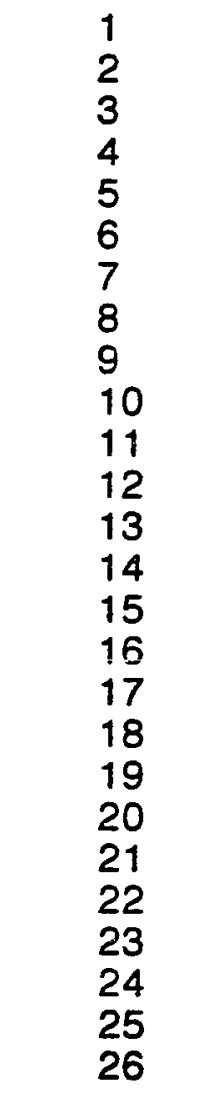 & $\begin{array}{l}23 \\
23 \\
18 \\
27 \\
26 \\
31 \\
27 \\
32 \\
34 \\
34 \\
26 \\
34 \\
18 \\
18 \\
26 \\
30 \\
34 \\
31 \\
22 \\
29 \\
30 \\
34 \\
35 \\
23 \\
29 \\
30\end{array}$ & $\begin{array}{l}M \\
M \\
F \\
F \\
F \\
F \\
M \\
M \\
F \\
M \\
M \\
M \\
F \\
M \\
M \\
F \\
F \\
M \\
F \\
F \\
M \\
F \\
F \\
F \\
M \\
M\end{array}$ & $\begin{array}{r}152 \\
190 \\
131 \\
151 \\
129 \\
142 \\
163 \\
148 \\
134 \\
170 \\
162 \\
179 \\
141 \\
163 \\
189 \\
157 \\
166 \\
200 \\
117 \\
154 \\
144 \\
91 \\
174 \\
128 \\
194 \\
177\end{array}$ & $\begin{array}{l}L \\
R \\
R \\
R \\
R \\
R \\
R \\
L \\
R \\
R \\
R \\
R \\
L \\
L \\
L \\
R \\
R \\
L \\
R \\
R \\
R \\
R \\
R \\
R \\
R \\
R\end{array}$ \\
\hline
\end{tabular}


APPENDIX G

\section{SPSS DATA FILE}

\begin{tabular}{llllllll}
\hline 01 & 23 & 1 & 152 & 2 & 41.5 & 27.6 & 38.2 \\
02 & 23 & 1 & 190 & 1 & 24.8 & 30.5 & 27.4 \\
03 & 18 & 2 & 131 & 1 & 23.5 & 23.3 & 16.5 \\
04 & 27 & 2 & 151 & 1 & 11.3 & 10.0 & 09.5 \\
05 & 26 & 2 & 129 & 1 & 47.7 & 44.0 & 49.9 \\
06 & 31 & 2 & 142 & 1 & 27.6 & 51.6 & 59.5 \\
07 & 27 & 1 & 163 & 1 & 33.9 & 27.4 & 32.4 \\
08 & 32 & 1 & 148 & 2 & 33.1 & 40.4 & 38.0 \\
09 & 34 & 2 & 134 & 1 & 17.9 & 17.3 & 22.4 \\
10 & 34 & 1 & 170 & 1 & 17.8 & 10.3 & 18.4 \\
11 & 26 & 1 & 162 & 1 & 09.5 & 07.3 & 09.1 \\
12 & 34 & 1 & 179 & 1 & 21.2 & 22.8 & 22.6 \\
13 & 18 & 2 & 141 & 2 & 13.7 & 13.6 & 13.9 \\
14 & 18 & 1 & 163 & 2 & 50.5 & 57.1 & 49.1 \\
15 & 26 & 1 & 186 & 2 & 28.0 & 26.8 & 22.5 \\
16 & 30 & 2 & 157 & 1 & 44.6 & 55.0 & 58.6 \\
17 & 34 & 2 & 166 & 1 & 10.8 & 11.6 & 10.7 \\
18 & 31 & 1 & 200 & 2 & 45.9 & 51.9 & 48.4 \\
19 & 22 & 2 & 117 & 1 & 17.1 & 17.9 & 20.3 \\
20 & 29 & 2 & 154 & 1 & 21.1 & 20.0 & 15.8 \\
21 & 30 & 1 & 144 & 1 & 15.0 & 14.6 & 10.0 \\
22 & 34 & 2 & 091 & 1 & 09.3 & 06.9 & 09.1 \\
23 & 35 & 2 & 174 & 1 & 29.4 & 28.6 & 25.5 \\
24 & 23 & 2 & 128 & 1 & 13.5 & 15.0 & 12.9 \\
25 & 29 & 1 & 194 & 1 & 28.1 & 25.6 & 24.8 \\
26 & 30 & 1 & 177 & 1 & 35.3 & 30.7 & 32.7 \\
& & & & & & & \\
\hline
\end{tabular}




\section{APFENDIX H SPSS DEFINITION FILE}

Data list file = 'a:foot.dat'

ID 1-2 age 4-5 gen 7 wt 9-11 leg 13 fpn 15-18 fper 20-23 fpir 25-28.

Variable labels ID 'ID number'

age 'age'

gen 'gender'

wt 'body weight'

leg 'dominant leg'

fpn 'neutral'

fper 'external rotation'

fpir 'internal rotation'

Value labels gen 1 'male' 2 'female'

leg 1 'right' 2 'left'.

List variables $=$ age to fpir.

Frequencies variables $=$ age to fpir.

Save file = 'foot.stm'. 


\author{
Get file = 'a:foot.stm'. \\ Process if (gen $=1$ ). \\ Frequencies variables $=\mathrm{fpn}$ to fpir \\ format $=$ notable/histogram \\ /statistics $=$ stdev. \\ Process if (gen=2). \\ Frequencies variables $=f p n$ to fpir \\ format $=$ notable/histogram \\ /statistics $=$ stdev.
}




\section{APPENDIX J \\ ANOVA TABLES FOR RELIABILITY}

Neutral

\begin{tabular}{llll}
\hline SOURCE & DF & SS & MS \\
\hline Between & 25 & 11124.64 & 444.9855 \\
Within & 2 & 56.13184 & 28.06592 \\
Interaction & 50 & 1579.105 & 31.58211 \\
Total & 77 & 12759.87 & \\
\hline
\end{tabular}

Reliability $=.93$

External Rotation

\begin{tabular}{llll}
\hline SOURCE & DF & SS & MS \\
\hline Between & 25 & 17062.82 & 682.5128 \\
Within & 2 & 56.72751 & 28.36376 \\
Interaction & 50 & 3964.604 & 79.29209 \\
Total & 77 & 21084.15 & \\
\hline
\end{tabular}

Reliability $=.89$

Internal Rotation

\begin{tabular}{llll}
\hline SOURCE & DF & SS & MS \\
\hline Between & 25 & 19064.35 & 762.574 \\
Within & 2 & 165.8221 & 82.91106 \\
Interaction & 50 & 2798.774 & 55.97548 \\
Total & 77 & 22028.95 & \\
\hline
\end{tabular}

Reliability $=.93$ 
APPENDIX K

\section{CALCULATIONS FOR PRACTICAL SIGNIFICANCE}

$$
\text { Practical Significance (atea) } \quad w^{2}=S_{b} / S S_{t}
$$

Neutral

$$
11124.64 / 12759.87=.87
$$

External Rotation

$$
17062.82 / 21084.15=.81
$$

Internal Rotation

$$
19064.35 / 22028.95=.87
$$

